\title{
EMPIRICAL IMPLICATIONS OF EQUILIBRIUM BIDDING IN FIRST-PRICE, SYMMETRIC, COMMON VALUE AUCTIONS
}

\author{
Kenneth Hendricks \\ Joris Pinkse \\ Robert H. Porter
}

Working Paper 8294

http://www.nber.org/papers/w8294

\author{
NATIONAL BUREAU OF ECONOMIC RESEARCH \\ 1050 Massachusetts Avenue \\ Cambridge, MA 02138 \\ May 2001
}

We received helpful comments from two referees, Mark Armstrong, Susan Athey, Phil Haile and Preston McAfee, and from the participants in a number of seminars. Hendricks and Pinkse received financial support from SSHRCC, and Porter from the NSF. The views expressed herein are those of the authors and not necessarily those of the National Bureau of Economic Research.

(C) 2001 by Kenneth Hendricks, Joris Pinkse and Robert H. Porter. All rights reserved. Short sections of text, not to exceed two paragraphs, may be quoted without explicit permission provided that full credit, including $\odot$ notice, is given to the source. 
Empirical Implications of Equilibrium Bidding in First-Price, Symmetric, Common Value Auctions

Kenneth Hendricks, Joris Pinkse and Robert H. Porter

NBER Working Paper No. 8294

May 2001

JEL No. C7, D4, L1

\begin{abstract}
$\underline{\text { ABSTRACT }}$
This paper studies federal auctions for wildcat leases on the Outer Continental Shelf from 1954 to 1970 . These are leases where bidders privately acquire (at some cost) noisy, but equally informative, signals about the amount of oil and gas that may be present. We develop a test of equilibrium bidding in a common values model that is implemented using data on bids and ex post values. We compute bid markups and rents under the alternative hypotheses of private and common values and find that the data are more consistent with the latter hypothesis. Finally, we use data on tract location and ex post values to test the comparative static prediction in common value auctions that bidders may bid less aggressively when they expect more competition.
\end{abstract}

\begin{tabular}{|c|c|c|}
\hline Kenneth Hendricks & Joris Pinkse & Robert H. Porter \\
\hline Department of Economics & Department of Economics & Department of Economics \\
\hline University of British Columbia & University of British Columbia & Northwestern University \\
\hline Vancouver, B.C. & Vancouver, B.C. & Evanston, IL 60208 \\
\hline Canada V6T 1 Z1 & Canada V6T $1 Z 1$ & and NBER \\
\hline and & & \\
\hline Department of Economics & & \\
\hline University of Texas & & \\
\hline Austin, TX 78712 & & \\
\hline
\end{tabular}




\section{Introduction}

Do bidders in auction markets behave as predicted by game theoretic models? In an environment with common values, this question is often rephrased by asking whether bidders account for the winner's curse. It has frequently been addressed in the literature by checking the reduced form prediction that bidders may bid less aggressively against more rivals. In a common value environment, the tendency to bid more aggressively under more competition is tempered by winner's curse considerations. Winning the auction is bad news to the extent that it reveals that the winning bidder's signal was more optimistic than that of the other bidders, and the greater the level of competition the worse the news associated with winning. However, Pinkse and Tan [24] show that this feature of bidding is not specific to the common value environment, in that equilibrium bids may also fall as competition increases in private affiliated value models. If an ex post measure of the value of the object being sold is available, an alternative research strategy is to compare bid levels to the value measure. Our previous work [II], [II] exploits the availability of ex post values to test equilibrium bidding models in common value environments with asymmetric information using drainage tract data. Drainage tracts are adjacent to tracts where oil and gas deposits have been found. The firms owning the adjacent tracts, called "neighbor" firms, have superior information to non-neighbors about tract value. The key feature of competitive bidding between informed and uninformed firms in first-price, common value auctions is that the latter participate, but their number is essentially irrelevant to the informed firm. Since neighbor firms could be identified, and because they behaved as a consortium, it was possible to test the theory by comparing the bidding behavior and the ex post profits of neighbor firms and nonneighbors.

In this paper we study bidding in first-price, sealed bid auctions with symmetric information using wildcat tract data. Wells drilled in search of new deposits of oil and gas are called wildcat wells. Wildcat tracts are located in areas that have not been drilled. Firms are allowed to conduct seismic studies prior to bidding for these tracts, but they are not permitted to drill exploratory wells. The seismic studies yield noisy signals about the value of the tract. Thus, firms are more or less equally informed, although they may have quite different opinions about the likelihood of finding oil and gas, depending upon the content and analyses of the surveys. Our primary objective is the same as in our study of drainage auctions: is bidding in wildcat auctions consistent with equilibrium behavior? We use the availability of data on ex post realizations of common tract value to develop several preliminary tests to determine whether firms are cognizant of the winner's curse. The tests compare bids against outcomes and most of them are not rejected. However, developing formal tests of equilibrium bidding in symmetric, common value auctions with entry requires a different approach than in asymmetric, common value auctions. 
Our main test for equilibrium bidding exploits the recent work by Laffont and Vuong [16] on structural estimation in first-price auctions. Applying a clever transformation of variables to the bidder's first order condition for optimality, they show that the bidder's valuation of the object can be expressed as a function of its bid and the distribution of the maximum rival bid. In private value environments, this valuation is the firm's expected value of the object conditional on its signal. As a result, the first order conditions can be used to nonparametrically identify the joint distribution of bidder valuations (after suitably normalizing the signals) as well as the firm's bid function. In common value environments, the first order condition identifies the firm's expected value of the object conditional on its signal being equal to the maximum signal of its rivals. Because this valuation depends on rivals' signals, it cannot be used to identify the firm's signal, and hence its bid function or the underlying distributions of signals. However, the conditional expectation can be estimated if data on bids and ex post realizations of the common tract value are available. Thus, instead of inferring this value from the first order condition, it is possible to test the condition directly. An important feature of the test is that it is not sensitive to unobserved tract heterogeneity. Because the bidder's first order condition must hold for each realization of tract characteristics, it must also hold in the aggregate.

Standard models of bidding take the number of bidders as fixed and known to the participants. In the Outer Continental Shelf (OCS) auctions, it is the number of firms that conduct or purchase seismic surveys that matters. If there is a binding reserve price, then not all participants necessarily bid. Consequently, the actual number of bidders may not be a good proxy for the level of competition. Furthermore, the number of firms that obtain seismic signals may not be known to the bidders since not all potential bidders choose to invest in surveys. Participation rates are typically less than 25 per cent in any given sale for any firm. We construct a measure of the set of potential bidders for a tract that is constructed from information on who bid in the local area. The assumption is that if a firm is interested in the area, then it will obtain a seismic survey covering some of the tracts in that area and bid on at least one tract. We condition our test of equilibrium bidding in a symmetric common value environment on this measure of competition. We find that the test is not rejected on the more competitive tracts. On the less competitive tracts, there is evidence of overbidding due to firms overestimating tract values. A model in which firms ignore the information from winning is rejected by the data.

The common value hypothesis has been criticized in the work of Li, Perrigne and Vuong [18], who adopt the alternative assumption that the bidding environment is private values. The two different valuation models can have quite different positive implications, such as the effect of increased competition. The model of valuations also affects normative issues, such as optimal auction design. Despite the important theoretical distinction between common and private valuation models, the empirical 
literature has struggled with the problem of distinguishing between them. Laffont and Vuong [16] show that, conditional on the number of potential bidders, bidding data alone are insufficient to distinguish nonparametrically between a common value model and an affiliated private values model. One approach for distinguishing between the two environments is to exploit exogenous variation in the number of bidders. The bidder valuation identified by the first order condition is independent of the number of potential bidders under the hypothesis of private values and is stochastically increasing under the hypothesis of common values. Haile, Hong and Shum [ 8$]$ provide a test based on this approach. The difficulty with applying this test to our data is unobserved heterogeneity. That is, consistent with our model of entry, the number of potential and actual bidders are correlated with tract value. We propose a test that exploits the availability of data on ex post values. We use this information to compute bid markups and rents under the alternative hypotheses of common and private values. The results suggest that the OCS data are more consistent with the common value model, and inconsistent with a private values model.

We also propose a strategy for identifying common value models when data on ex post values are available. Our strategy consists of imposing a moment restriction on the joint distribution of a bidder's signal and the common value. In particular, we assume that bidders' posterior estimates of the common value are unbiased. This restriction is sufficient to identify the inverse bid function, which we estimate separately on the more competitive and less competitive tracts. Our approach to resolving the non-identification problem in common value auctions does not assume rational bidding. That is, in contrast to other papers on structural estimation in auctions, our method is not based upon the bidders' first order conditions.

The literature on structural estimation of auction models has focussed primarily on the private value environment. The early work by Smiley [26], Paarsch [2:3], and Donald and Paarsch [5] take a parametric approach, restricting the class of joint distributions to those which admit a closed form solution for the bid function, and then using maximum likelihood methods to estimate the unknown parameter vector. Laffont, Ossard and Vuong [15] develop a simulated nonlinear least squares estimator which exploits the fact that, in the symmetric independent private values (IPV) environment, the bid function can be expressed as a conditional expectation of a second-order statistic. Elyakime, Laffont, Loisel and Vuong [6] derive a nonparametric estimation method for estimating the bidder's inverse bid function, which has a closed form solution in an IPV value environment. Li, Perrigne and Vuong [18] extend the nonparametric method to conditionally independent private values environments (CIPV). Li, Perrigne and Vuong [17] also show how to extend this method to affiliated private values (APV) environments. Bajari [I] uses Bayesian likelihood methods in an IPV model with asymmetric bidders. Hong and Shum [12] and Bajari and Hortacsu [3] estimate structural models of common value (CV) auctions by assuming a parametric 
form for the joint distribution of signals and common value.

The paper is organized as follows. In Section 2 we present the theoretical model. In Section 3 we describe how the federal government sells rights to oil and gas properties on offshore lands and present the data. Section 4 provides evidence that bidders bid rationally. We classify tracts into two sets, a highly competitive set in which the number of potential bidders is larger than six and a less competitive set in which the number of potential bidders does not exceed six. For each category, we examine the relationship between ex post returns and bids and provide a measure of the winner's curse. The results indicate that bidders bid less than their expectation of the value of the tract and less aggressively on the more competitive set of tracts. In Section 5 we develop and implement a test of equilibrium bidding in $\mathrm{CV}$ environment. In Section 6 we estimate the bid function. In Section 7 we discuss the common value assumption. Concluding remarks are contained in Section 8.

\section{The Model}

We adopt the convention of denoting parameters in lower case, random variables in upper case, and realizations of random variables in lower case.

Consider a first-price, sealed bid auction in which $l$ potential bidders compete for the production rights of a single tract. The announced minimum bid is $r$. Prior to bidding, each potential bidder must decide whether to become more informed about the tract by investing in a seismic survey. A potential bidder who does not invest in a survey does not bid. Those who invest in a survey are called active bidders. Each active bidder must then decide whether and how much to bid conditional on the seismic information obtained. If the information is not favorable, then an active bidder may believe that the tract is not worth $r$ and hence choose not to bid. An active bidder who decides to bid is called an actual bidder. Thus, a potential bidder is observed to bid if and only if it believes that the prospect of finding oil is sufficiently high to justify a costly survey, and those beliefs are confirmed by the survey.

Let $V$ denote the unknown, common value of the oil and gas deposit. Let $Z_{i}$ denote a potential bidder i's private estimate of the value of the tract prior to investing in a seismic survey. The seismic survey provides an active bidder $i$ with a private, realvalued information signal $S_{i}$ that is drawn from a distribution with support $[\underline{s}, \bar{s}]$. The random variables $\left(V, Z_{1}, \ldots, Z_{l}\right)$ are affiliated which, loosely speaking, implies that higher realizations of some of the components make higher realizations of the remaining components more likely. The joint distribution of $\left(V, Z_{1}, \ldots, Z_{l}\right)$ is assumed to be exchangeable with respect to bidder indices. A potential bidder invests in a survey if its estimate exceeds a common threshold level. Thus, the number of active bidders, $N$, is a random variable that is affiliated with $V$. Let $K=N-1$ denote the 
number of rivals of an active bidder. The random variables $\left(V, S_{1}, \ldots, S_{l}\right)$ are assumed to be strictly affiliated and exchangeable with respect to the bidder indices.

The assumptions of affiliation and exchangeability are standard for models with an exogenous number of bidders. However, in our model, participation is endogenous and potentially informative. We will need to impose two additional restrictions.

Information Assumptions: (i) $\left(Z_{1}, \ldots Z_{l}\right)$ are independent conditional on $V$ 円, and (ii) $V$ and $Z_{i}$ are independent conditional on $S_{i}$.

The purpose of the information assumptions is to make pre-seismic information redundant for active bidders. They imply that $S_{j}$ and $K$ are independent of $Z_{i}$ conditional on $S_{i}$ for $i \neq j$.2 Thus, the beliefs of an active bidder about the value of the tract, the number of active rivals, and rival signals do not depend upon private information that it may have held prior to acquiring the seismic information. In addition, private information held by potential bidders who do not become active is not relevant to an active bidder's assessment of the tract. Thus, there is no selection problem in restricting the set of players in the bidding game to active bidders.

The value of the tract to an active bidder $i$ is given by $U_{i}=u\left(V, S_{i}\right)$ where $u$ is non-negative, continuous and increasing in both arguments. All of the bidder utilities depend upon the common component in the same manner and, for the moment, each bidder's utility is also allowed to depend upon its own seismic signal. Note that it is restrictive to assume that the signal $S_{i}$ is a scalar, as opposed to a vector. In a more general environment, bidders might have private information about the common component of value, $V$, as well as private components of value.

Let $F$ denote the cumulative distribution function of the $l+2$ vector $\left(N, V, S_{1}, \ldots, S_{l}\right)$. If $n<l$, then the distribution function of the $n+1$ vector $\left(V, S_{1}, \ldots, S_{n}\right)$ is derived from $F$ by conditioning on $N=n$ and setting $S_{n+j}=\bar{s}$ for $j=1, \ldots, l-n$. The $n+1$ vector is assumed to have a density $f$. The distribution function $F$ and the utility function $u$ are common knowledge. Each active bidder $i$ knows the value of his signal $s_{i}$ but does not know the signals of the other active bidders. Anecdotal evidence suggests that the decision to acquire detailed survey information is private,,$^{3}$ in which case the number of active bidders is not known to the bidders. For the purposes of this paper, we can be agnostic on this issue.

Our model is similar to that of McAfee and Vincent [2]], who extend the model referred to by Laffont and Vuong [16] as the Affiliated Value (AV) model to the case

\footnotetext{
${ }^{1}$ Conditional independence is a consequence of the exchangeability of an unbounded number of random variables and thus, for $l$ large, is a reasonable restriction on the joint distribution.

${ }^{2}$ An example that satisfies the Information Assumptions is one in which $S_{i}=V+\varepsilon_{i}$ and $Z_{i}=$ $S_{i}+\eta_{i}$, where $\varepsilon_{i}$ and $\eta_{i}$ are indiosyncratic shocks.

${ }^{3}$ For example, some of the potential bidders may purchase geological survey information from corporations that specialize in such activities. Other bidders, such as Shell, typically conduct their own surveys.
} 
of a stochastic number of bidders. The AV model was first introduced by Wilson [2.9] and is a special case of the general symmetric model of Milgrom and Weber [22]. In the AV model, the signals of other bidders affect the expected utility of bidder i through their affiliation with $V$, but they do not enter as arguments of the utility function. Two special cases will be of interest. The model is said to be a Common Value (CV) model when $U_{i}=V$; it is called an Affiliated Private Value (APV) model when $U_{i}=S_{i}$.

In deriving the equilibrium, we take the perspective of bidder 1 . But before specifying his optimization problem, we require some notation. Let $p(s)=\left(p_{1}(s), . ., p_{k}(s), . . p_{l}(s)\right)$ where $p_{k}(s)$ denotes the probability that bidder 1 faces $k$ rival bidders given signal $s$. Define $Y_{1}$ as the maximum signal among bidder 1's rivals conditional on the event that bidder 1 has at least one active rival, and zero when bidder 1 has no rivals. Let $H_{Y_{1} \mid S_{1}}(\cdot \mid s)$ denote the cumulative distribution of $Y_{1}$ when bidder 1 has obtained signal $s$ and has at least one rival bidder. Let $h_{Y_{1} \mid S_{1}}(\cdot \mid s)$ denote the associated density function. Then,

$$
H_{Y_{1} \mid S_{1}}(y \mid s)=\sum_{k=1}^{l-1} \frac{p_{k}(s)}{1-p_{0}(s)} F_{Y_{1} \mid S_{1}, K}(y \mid s, k) .
$$

Note that the probability weights have been normalized to sum to 1 by conditioning on the event that bidder 1 has at least one active rival. Define

$$
w(s, y)=E\left[u(V, s) \mid S_{1}=s, Y_{1}=y, K \geq 1\right]
$$

to be bidder 1's expected value from the tract when his signal is $s$ and the maximum of his rivals' signals (assuming $k \geq 1$ ) is $y$. When bidder 1 has no active rivals, his expected value is given by

$$
w(s)=E\left[u(V, s) \mid S_{1}=s\right] .
$$

Affiliation imposes considerable structure on bidder 1's beliefs about $K$ and $Y_{1}$, and his expected value. We gather the important results in the lemma below. Note that, conditional on $K \geq 1, Y_{1}$ is affiliated with $S_{1}$ since it is the maximum of a finite, positive number of random variables that are affiliated with $S_{1}$.

Lemma 1 (i) $p(s)$ first order stochastically dominates $p\left(s^{\prime}\right)$ for $s^{\prime}>s$, (ii) $\frac{H_{Y_{1} \mid S_{1}}(y \mid s)}{h_{Y_{1} \mid S_{1}}(y \mid s)}$ is decreasing in $s,($ iii) $w(s)$ and $w(s, y)$ are increasing functions.

The proof of Lemma 1 follows standard arguments in the literature and is not repeated here. 
Suppose that each rival adopts the monotone increasing bidding strategy $\beta(s)$ with inverse $\eta(b)$. Under the assumption of risk neutrality, bidder 1's optimization problem consists of choosing $b \geq r$ to maximize

$$
\Pi(b, s)=\left(1-p_{0}(s)\right) \int_{\underline{s}}^{\eta(b)}(w(s, y)-b) h_{Y_{1} \mid S_{1}}(y \mid s) d y+p_{0}(s)(w(s)-b) .
$$

The first order condition for a maximum is

$$
\left(1-p_{0}(s)\right)\left[\{w(s, \eta(b))-b\} h_{Y_{1} \mid S_{1}}(\eta(b) \mid s) \eta^{\prime}(b)-H_{Y_{1} \mid S_{1}}(\eta(b) \mid s)\right]-p_{0}(s)=0 .
$$

If bidder 1's best reply is $b=\beta(s)$, then, substituting for $b$, equation (2) can be expressed as a differential equation:

$$
\left(1-p_{0}(s)\right)\left[(w(s, s)-\beta(s)) \frac{h_{Y_{1} \mid S_{1}}(s \mid s)}{\beta^{\prime}(s)}-H_{Y_{1} \mid S_{1}}(s \mid s)\right]-p_{0}(s)=0 .
$$

Active bidders who obtain very low signals from their seismic surveys are unlikely to bid. Define

$$
s^{*}(r)=\inf \left\{s:\left(1-p_{0}(s)\right) E\left[w\left(s, Y_{1}\right) \mid S_{1}=s, Y_{1}<s\right]+p_{0}(s) w(s) \geq r\right\}
$$

to be the lowest signal at which a bidder believes the value of the tract conditional on winning (in a symmetric equilibrium) is worth at least the reserve price. We assume that $s^{*}(r)$ exists and exceeds $\underline{s}$, the lower bound of the support of $S_{i}$. Hence, the reserve price is binding, and the boundary condition for solving the above differential equation is $\beta\left(s^{*}\right)=r$. We define $\beta(s)=0$ for $s<s^{*}$.

McAfee, Quan, and Vincent [20] have observed that affiliation of $\left(V, S_{1}, . ., S_{l}\right)$ is not sufficient to ensure existence of an equilibrium in increasing bid functions when the number of bidders is stochastic. The problem is that the event of bidding against zero rivals (i.e., no maximum rival signal) and the event of bidding against one or more rivals are not ordered. When $N$ is affiliated with $S_{i}$ and the reserve price is binding, the condition required for monotonicity is more likely to hold, and we shall assume that this is the case for oil lease auctions.

\footnotetext{
${ }^{4}$ If $N$ is independent of $V$, then Lemma 1 is sufficient for existence since $p_{0}$ is a constant.

${ }^{5}$ A straightforward application of Milgrom and Weber's proof for existence (Theorem 14) requires one to show that the term

$$
\left(1-p_{0}(s)\right)[w(s, x)-\beta(x)]-\beta^{\prime}(x)\left\{\frac{p_{0}(s)+H_{Y_{1} \mid S_{1}}(x \mid s)}{h_{Y_{1} \mid S_{1}}(x \mid s)}\right\}
$$

has the same sign as $(s-x)$. Lemma 1 is sufficient if $p_{0}$ is zero but it is not otherwise.
} 
The important insight offered in Elyakime, Laffont, Loisel and Vuong [6] is that, for empirical purposes, it is more useful to invert the above equilibrium relation and express the signal as a function of the bid and the distribution of bids. Define $M_{1}$ to be the highest bid submitted by bidder 1's rivals or, in the absence of a rival bid, the reserve price. Note that the latter event can occur in two ways: either bidder 1 has no rivals or all of bidder 1's rivals have signals less than $s^{*}$. The two events are not distinguishable empirically, which is why it is important to define $M_{1}$ as we have rather than as the maximum bid of bidder 1's rivals. The latter random variable is not observable if $r$ is binding. Let the conditional distribution of $M_{1}$ given $B_{1}$, the bid of the firm in question, be denoted by $G_{M_{1} \mid B_{1}}(\cdot \mid \cdot)$ and its density by $g_{M_{1} \mid B_{1}}(\cdot \mid \cdot)$. Note that monotonicity of $\beta$ and $\eta$ implies, for any $b>r$,

$$
G_{M_{1} \mid B_{1}}(m \mid b)=\left[1-p_{0}(\eta(b))\right] H_{Y_{1} \mid S_{1}}(\eta(m) \mid \eta(b))+p_{0}(\eta(b)) .
$$

The first term is the probability that the highest bid among bidder 1's rivals is less than $m$ conditional upon bidder 1's bid of $b$ and the event of at least one rival; the second term is the probability that bidder 1 has no rival. Note that $\{M=r\}$ occurs with positive probability, so $r$ is a point of discontinuity for $G_{M_{1} \mid B_{1}}$. It is continuous and differentiable on $(r, \infty)$ with density function

$$
g_{M_{1} \mid B_{1}}(m \mid b)=\frac{\left(1-p_{0}(\eta(b))\right) h_{Y_{1} \mid S_{1}}(\eta(m) \mid \eta(b))}{\beta^{\prime}(\eta(b))} .
$$

Substituting the above relations into equation (3) yields, for $b>r$,

$$
w(\eta(b), \eta(b))=b+\frac{G_{M_{1} \mid B_{1}}(b \mid b)}{g_{M_{1} \mid B_{1}}(b \mid b)} \equiv \xi(b, G) .
$$

In a series of papers, Vuong and his coauthors have used equation (4) to develop nonparametric estimators for $F$ and $\beta$ in private value environments. Recall that when valuations are private, $w(s, s)=s$, and $\xi$ can be interpreted as the inverse bid function. Guerre, Perrigne and Vuong [ [ $]$ consider the independent private value environment, Li, Perrigne, and Vuong [17] consider affiliated private values, and Li, Perrigne, and Vuong [18] conditionally independent private values. The assumption of private values is crucial. Laffont and Vuong have shown that it is not possible to use equation (4) to identify $F$ or $\beta$ in common value environments, at least not without making strong parametric assumptions about $u$ and $F$.

We are interested primarily in testing equilibrium bidding behavior. The first test was developed by Laffont and Vuong for private affiliated value environments but is easily extended to environments with a common component and a stochastic number of bidders. Lemma 1 implies that $w(s, s)$ is increasing in $s$. Therefore, if equation (4) 
holds, then $\xi(b, G)$ must be monotone increasing in $b$. If it is not, the data generating mechanism is not a symmetric Bayesian Nash equilibrium in monotone increasing bid functions. This test is essentially a joint test of affiliation, symmetry and equilibrium.

Our second test is novel but specific to environments that satisfy the following assumption.

Preference Assumption: $u\left(V, S_{i}\right)=V$.

Given the above assumption,

$$
w(s, s)=E\left[V \mid S_{1}=s, Y_{1}=s\right] .
$$

Define the conditional expectation function,

$$
\zeta(b)=E\left[V \mid B_{1}=b, M_{1}=b\right] .
$$

In principle, $\zeta$ can be estimated if, in addition to bids, data on the realizations of the common value $V$ are available, as is the case in our data set on oil and gas auctions. Monotonicity of $\beta$ implies that for $b>r$,

$$
\zeta(b)=w(\eta(b), \eta(b)) .
$$

At $b=r$, the definition of $M_{1}$ implies that

$$
\zeta(r)=\left(1-p_{0}\left(s^{*}\right)\right) E\left[V \mid S_{1}=s^{*}, Y_{1}<s^{*}\right]+p_{0}\left(s^{*}\right) E\left[V \mid S_{1}=s^{*}\right]=r<w\left(s^{*}, s^{*}\right) .
$$

In other words, $\zeta$ exhibits a downward discontinuity at $r$ due to the possibility of no rival bid. But, for $b>r$, if bidding is according to a symmetric Bayesian Nash equilibrium, then

$$
\zeta(b)=\xi(b, G)
$$

Equation (5) is an empirically testable implication of equilibrium bidding in the common value environment.

We also test a variation on our model in which firms choose bids to maximize the expression given in equation (1) but where $w(s)$ replaces $w(s, y)$ in the integrand. We will refer to this model as the myopic bidding model. An interpretation is that, in choosing its bid, each firm's beliefs about the probability of winning are consistent with the true probability law but its beliefs about the value of the tract conditional on winning are not. In particular, its expectations are based solely on its own signal, and it ignores the "bad news" associated with the event of winning. Deriving the first-order conditions and applying the same transformation of variables as above yields the first-order condition

$$
w(\eta(b))=\xi(b, G)
$$


Define $\gamma(b)=E\left[V \mid B_{1}=b\right]$. As in the case of $\zeta$, the function $\gamma$ can be estimated from the data on bids and realizations of the common value $V$. Monotonicity of the bid function then implies that $\gamma(b)=w(\eta(b))$. Consequently, one can test the myopic bidding model by testing the equality

$$
\gamma(b)=\xi(b, G)
$$

Note that this equality must hold for $b \geq r$, since the participation rule in the myopic model is to bid as long as $w(s)$ exceeds $r$.

\section{Auction Mechanism and Data}

The U.S. government holds the mineral rights to offshore lands more than three miles from the coast, out to the 200 mile limit. The states own the rights out to the three mile mark. Beginning in 1954, the federal government has transferred production rights on its lands to the private sector by a succession of lease sales in which hundreds of leases have been auctioned. A wildcat lease sale is initiated when the Department of Interior (DOI) announces that certain offshore areas are available for exploration, and nominations are invited as to which tracts should be offered for sale. A tract is typically a block of 5,000 or 5,760 acres, or half a block. The number of tracts available in a sale is usually well over one hundred and tracts are often scattered over several different areas.

Prior to the sale, and often prior to the announcement of the sale, firms conduct seismic surveys on selected tracts. The time between announcement and sale date is at most several months, since DOI is required to give only thirty days notice. A survey provides information about the geology of the tracts and is used by a firm to determine which tracts to bid and how much to bid. The cost of a detailed survey has been reported to vary between $\$ 9$ to $\$ 26$ per acre, including payments to the geologists to study and interpret the seismic data. Some firms conduct their own surveys while others purchase surveys from geophysical firms that specialize in this type of activity. Many aspects of the firm's tract evaluations are private, including which tracts were selected for investigation. In particular, given the cost of a tract survey, it is not an equilibrium for all firms known to be interested in acquiring leases in an area to survey all tracts. Individual firms typically select a fraction of the available tracts and the locations of these tracts are reputedly a closely guarded secret.

A firm can choose either to bid solo or jointly with other firms. A joint bid in offshore auctions consists of two or more firms combining to submit a single bid and sharing the costs and revenues if their bid is the high bid. Prior to 1975, this practice was legal for all firms. In late 1975, DOI adopted regulations barring the eight largest crude oil producers worldwide (Exxon, Gulf, Mobil, Shell, Standard Oil 
of California, Standard Oil of Indiana, Texaco and British Petroleum) from bidding with each other on the grounds that the practice was reducing prices. Joint bidding groups are frequently sale-specific and form after the announcement of the sale.

The nominated tracts in a sale are sold simultaneously in a first-price, sealed bid auction. The announced reserve price for tracts in our sample is $\$ 15$ per acre. A participating bidder or consortium of bidders submits a separate bid on each tract that it has an interest in acquiring. A bid is a dollar figure, known as a bonus. At the sale date, DOI opens the envelopes and announces the value of the bids that have been submitted on each tract and the identities of the bidders. The firm or consortium that submits the highest bid on a tract is usually awarded the tract at a price equal to its bid. In practice, the government could and did reject bids above the stated minimum price. The rejection rate was less than $10 \%$ on wildcat tracts and usually occurred on marginal tracts receiving only one bid (Porter [25]). We will largely ignore this factor in our analysis.

When a firm or consortium is awarded a tract, it has 5 years to explore it. If no work is done during the lease term (i.e., no wells are drilled), ownership reverts to the government and the tract may subsequently be re-offered. A nominal fee, typically $\$ 3$ per acre, is paid each year until either the lease is relinquished or production begins. If oil or gas is discovered in sufficient quantities, the lease is automatically renewed as long as production occurs. A fixed fraction of the revenues from extraction accrues to the government as royalty payments. The royalty rate for tracts in our sample is $1 / 6$.

We restrict attention to sales of wildcat tracts off the coasts of Texas and Louisiana held during the period 1954 to 1970 inclusive. The reason for doing so will become clear in the next section.

\subsection{The Variables}

We turn next to the task of measuring the variables identified in the theoretical model and discuss the associated measurement problems. Recall that the theoretical model identified four variables of interest: $V_{t}$, the value of the oil and gas deposit on tract $t$; $B_{i t}$, the bid of bidder i on tract $t ; M_{i t}$, the maximum bid of bidder i's rivals on tract $t$ or, in the absence of a rival bid, the reserve price; and $l_{t}$, the number of potential bidders on tract $t$. The information available for each tract receiving at least one bid are the date of sale; acreage; location; the identity of all bidders and the amounts they bid; the identity of participants in joint bids and their shares in the bid; whether the government accepted the high bid; the number, date, and depth of any wells that were drilled; and monthly production through 1991 of oil, condensate, natural gas, and other hydrocarbons.

The ex post value of a tract is defined to be discounted revenues less discounted 
drilling costs and royalty payments. We converted production flows into revenues using the real wellhead prices at the date of the sale, and discounted them to the auction date at a 5 percent per annum rate. The American Petroleum Institute conducts an annual survey of drilling costs of wildcat and production wells for different regions including off-shore Louisiana and Texas. We used these estimates, and information on well depth, to compute drilling costs for each tract, classifying wells as productive if the tract produced hydrocarbons and exploratory if it did not. These costs are discounted to the auction date at a 5 percent per annum rate. Royalty payments are computed from the discounted revenues by multiply this number by $1 / 6$. Tracts not drilled are given a value of zero.

There are several potential sources of error in our measure of ex post value. These include the wellhead prices, production levels, discount rate, and drilling costs. The use of wellhead prices at the auction date assumes that firms' have identical and constant expectations about the future prices of oil. The assumption of static expectations is plausible for sales held between 1954 and 1970 because real prices were virtually constant during this period. But it is clearly implausible for sales held after 1973 when prices at auction dates differed considerably from actual prices over the production life of the tracts. This is why we restricted our sample period and dropped sales held after 1970. However, revenues are based on production through 1991. PostOPEC prices were considerably higher than prices during our sample period. If production flows depend on actual prices, our measure of revenues overestimates firms' expectations at the auction date. The discount rate matters because drilling costs must be incurred before production revenues are realized, and production may occur for decades. Production histories are truncated in 1991, which introduces a downward bias in our measure of ex post values for some tracts although the magnitude of the error is likely to be small when it is discounted back to the auction date. The average production horizon was 15 years. Finally, if there are differences in drilling costs across firms, the survey numbers we use contain a bias, as only the auction winners are surveyed. Unfortunately, the reported survey results do not distinguish among firms.

Should all bids on a tract be included? Our theoretical model assumes that the potential bidders on a tract are symmetric. However, hundreds of firms bid infrequently. They were unlikely to be as experienced and informed as the major bidders and were probably not perceived as serious competitors by the major bidders. We treat these firms as "noise" bidders, and focus our tests of rational bidding on the twelve firms and bidding consortia with the highest participation rates in our sample. Table 1 lists these major bidders and their bidding activities. The three bidding consortia pooled their exploration budgets and expertise and bid almost exclusively with each other. We treat these consortia as single firms. The twelve firms and consortia are designated as large firms, which we call the Big12. All other firms are 
referred to as fringe firms. For the purposes of this paper, we define a joint bid as one in which two or more large firms participated. All other bids are called solo bids. The first two columns of Table 1 give the number of solo and joint bids of each large firm. The twelve large firms account for about $80 \%$ of all bids in our sample.

For each tract $t$, we select only bids by Big12 firms and, for the remainder of the paper, the index $i$ indexes one of the Big12 firms. However, in defining $M_{i t}$, the maximum of the highest rival bid and the reserve price, we include all bidders, including the fringe bidders. The reason is that a Big12 firm's beliefs about winning when it submits a bid should be consistent with the actual probability of winning at that bid, which includes the possibility of a fringe bid.

Our measure of $l_{t}$, the number of potential bidders on tract $t$, is constructed from information on who bid in the area and when. For tracts that were drilled, location is identified by the longitudinal and latitudinal coordinates of the well. Tracts that were not drilled are assigned coordinates by interpolation from nearby tracts that were drilled.I On average a tract covers 0.0463 degrees of longitude and 0.0405 degrees of latitude. A neighborhood for tract $t$ consists of all tracts whose registered locations are within 0.1158 (2.5 times 0.0463) degrees of longitude and 0.1012 (2.5 times 0.0405) degrees of latitude of tract $t$ and that were offered for sale at the same time as or before tract $t$. Ignoring irregular tract sizes and boundary effects, the maximum possible size of a neighborhood is 25 tracts or 125,000 acres.

An obvious approach to defining the number of potential bidders on a tract is simply to count the number of Big12 firms that bid on the tract or in its neighborhood. The rationale is that if a Big12 firm is interested in the area, then it will probably bid on at least one tract. The main difficulty with this measure is the treatment of joint bids. Firms that submit solo bids on tract $t$ are counted as potential bidders since they are revealed to be active. Firms that submitted a joint bid on tract $t$ are treated as a single competitor, regardless of how they bid on other tracts in the neighborhood of tract $t$. The implicit assumption here is that joint ventures are known to competitors..$^{8}$ We also include firms that did not bid on tract $t$ but submitted solo bids on at least one tract in the neighborhood. Firms that did not bid on tract $t$ and submitted only joint bids with each other on tracts in the neighborhood of tract $t$ are

\footnotetext{
${ }^{6} \mathrm{~A}$ small number of tracts registered multiple bids by a firm. This problem arose in part due to classification errors in identifying a firm's subsidiaries and affiliates. We adopted the following rule for these bids. If a subset of the participants in one bid participated in another bid, the latter is dropped. Thus, solo bids of bidders who also submitted joint bids are eliminated. In the other cases, the highest bid is taken and the others dropped.

${ }^{7} \mathrm{~A}$ small number of tracts were sufficiently isolated that it was not possible to interpolate their location from nearby tracts. These tracts were dropped from the sample.

${ }^{8}$ We alsocalculated the number of potential bidders under the alternative hypothesis that joint ventures are private. However, the qualitative results did not change.
} 
also counted as single competitors.

Our measure of the number of potential bidders on a tract may overstate the true level of competition. Solo bids are always treated as evidence of competitive behavior. But firms could coordinate bidding strategies by agreeing to bid solo on different sets of tracts rather than bidding jointly. Our measure does not capture this form of collusion. On the other hand, firms known to be interested in the area but who decided not to bid on any tracts in the neighborhood of tract $t$ are not counted in $l_{t}$. We might then underestimate the number of potential bidders.

The third column of numbers in Table 1 reports the number of tracts where each large firm is counted as a potential bidder. The fourth column gives each firm's bid participation rate on tracts where it is a potential bidder. Note that this column is the relevant one for evaluating the validity of the symmetry assumption. It reveals that the variation in participation rates across firms is considerably less than the variation in bid frequency rates (i.e., the number in column 3 divided by 1260, the number of tracts receiving bids in the sample). The participation rates of most firms fall between 30 and 47 per cent. The AGCC consortium is the outlier with a participation rate of $54 \%$. In contrast, bid frequency rates vary more or less uniformly between 13 per cent (Phillips) and 44 per cent (AGCC).

We conclude by noting one important feature of the data that is not incorporated into the theoretical model. The location of the oil and gas deposits are spatially correlated. That is, the random variables $\left\{V_{t}\right\}_{t=1}^{T}$ are not independent. The spatial correlation in deposits is reflected in the difference between the Big12 firms' bid frequency and participation rates. It would be surprising, therefore, if signals obtained by a firm on tracts in the neighborhood of tract $t$ are not informative about tract $t$. The theoretical model ignores this spatial dependence by treating the bid decisions on tracts as separate, independent decisions. Our hope is that information spillovers do not invalidate our tests of rational bidding. However, in evaluating the statistical significance of our tests, we do not ignore spatial correlation.

\subsection{Sample Statistics}

Table 2 provides summary statistics on wildcat sales in our sample. Typically, at least one bid was submitted on approximately 50 per cent of the tracts offered in a sale. Big12 firms typically bid on over 80 per cent of the tracts receiving bids in any given sale. The government rejected the high bid on 7 per cent of the tracts receiving bids. The unsold tracts receiving bids are mostly in later sales, and are mostly marginal tracts. The fraction of tracts drilled and the fraction of hits (i.e., productive tracts) among those that were drilled do not vary much across the larger sales, and are typically about $75 \%$ and $50 \%$ respectively. Mean discounted revenues on productive

tracts are similar across the larger sales, with the notable exception of the sale in 1968 
where revenues were only $\$ 12.2$ million per tract. (All dollar magnitudes are in 1982 dollars.) Mean discounted net revenues are net of royalty payments and discounted costs. They are calculated for all tracts, including "dry" tracts. Mean net revenues vary considerably across the sales, averaging $\$ 10.5$ million per tract across the sales. The average winning bid for the entire sample is $\$ 6.2$ million, which yields an average "rent" of $\$ 4.3$ million per tract. The average winning bid is substantially higher in later sales.

Our sample consists of all wildcat tracts receiving bids in the nine sales held between 1954 and 1970. Table 3 provides summary statistics on these tracts. The tracts are classified by the number of potential bidders, which ranges from 0 to 12 . Recall that our count of potential bidders includes only Big12 firms, and there is potential competition from fringe firms even when a firm knows it is the only large potential bidder (i.e., $l=1$ ). For each value of $l$, the first row gives the number of tracts, the second gives the number of bids per tract, and the third gives the number of Big12 bids per tract. The frequency distribution is approximately bi-modal, with peaks at $l=3$ and 9 , and a median of 7 . The number of bids is positively correlated with, but often considerably smaller than, the number of potential bidders. Even when all of the Big12 bidders are potential bidders, the average number of bids is only 4.25. Note the sharp increase in the average number of bids at the median, from 2.80 to 3.94. A comparison of rows two and three reveals that the probability of a fringe bid increases with $l$, and on average there is one fringe bid. This suggests that excluding fringe firms is probably not introducing too much error in our measure of competition. Ex ante expectations, as measured by the high bid, are positively correlated with $l$. The average high bid increases from $\$ 600$ thousand on tracts where none of the Big12 firms are potential bidders to $\$ 13.1$ million on tracts where every Big12 firm is a potential bidder. Note that there is a relatively large increase in the level of the high bid when $l$ increases from 6 to 7 . The percentage of tracts drilled increases with the number of potential bidders but the hit rate, defined relative to the number of tracts drilled, appears to be independent of the number of potential bidders for $l$ greater than 2, fluctuating between 40 and 55\%. Average revenue on productive tracts is quite noisy and does not exhibit any trend as $l$ increases. Net revenue is higher on the more competitive tracts but once again the relationship between these variables and $l$ is noisy and not monotonic. By contrast, average hit rates and revenues are strongly correlated with the number of bids (Porter [25]).

We also computed (but do not report) the average high bid, acreage bid, hit rate, average revenue and net revenue for neighborhoods of tracts with $l$ potential bidders. The neighborhood variables all tend to increase with $l$, which reflects the spatial correlation in deposits. In any region, one or two tracts receive most of the action and competition tends to diminish the further away one gets from the center of interest. The fraction of acreage in the neighborhood sold as wildcat tracts before or 
after tract $t$ is typically quite small. One reason is that the federal offshore lands have been explored in a series of bands that extend along the coastline and move outward over time from the shoreline further into the Gulf of Mexico. As a result, most of the tracts in the neighborhood of tract $t$ that were sold as wildcat tracts were sold in the same sale as tract $t$. The other reason is that any tract in the neighborhood of tract $t$ that is sold in a later sale is likely to be classified as a drainage or development tract.

In the analysis that follows, we exclude tracts where the high bid was rejected, and include only those with at least one Big12 potential bidder. The focus on Big12 bids excludes tracts with $l_{t}=0$. An argument for dropping tracts with $l_{t}=1$ is that the bidding behavior of the Big12 firm on these tracts is likely to differ from tracts where it knows it is competing against at least one other Big12 firm. However, there is still potential fringe competition on tracts with one potential Big12 bidder. Moreover, there are relatively few tracts in this category, and the results are similar when these tracts are excluded.

We stratify the sample according to two categories of the number of potential bidders, high and low. The low category is defined by $1 \leq l_{t} \leq 6$, and the high category by $l_{t}>6$. The highly competitive set has 752 tracts and the less competitive set has 501 tracts. Table 4 presents the frequency distribution of (base 10) log bid for each category. Not surprisingly, the low $l$ distribution has many fewer bids than the high $l$ distribution. Most of the density of the low $l$ distribution lies in the range 5.4 to 7.0 , which corresponds to bids of $\$ 250$ thousand to $\$ 10$ million. The main difference between the low $l$ and high $l$ distributions, apart from the number of bids, is that the latter contains relatively more high bids. There is a substantial number of bids in the interval 7.0 to 7.8 (\$10 million to $\$ 60$ million) on high $l$ tracts.

The classification of tracts into highly competitive and less competitive sets accounts for some tract heterogeneity. The following table, which is related to Table 3 , illustrates this point.

\begin{tabular}{|c|c|c|c|c|}
\cline { 2 - 5 } \multicolumn{1}{c|}{} & Hibid & Drill Rate & Hit Rate & NetRev \\
\hline Low $l$ & $\$ 2.76$ & 70.3 & 45.6 & 8.00 \\
\hline High $l$ & $\$ 8.51$ & 81.7 & 48.4 & 12.12 \\
\hline
\end{tabular}

Clearly, the high $l$ tracts are more likely to be productive than low $l$ tracts. For example, net revenues per productive tract are $52 \%$ higher on the more competitive set than on the less competitive set. This partially explains why the average high bid is higher on high $l$ tracts than on low $l$ tracts. 


\section{Preliminary Tests of Rational Bidding}

In this section we implement several tests of bidder rationality. These tests are essentially comparisons of bids and ex post outcomes

A basic test is that actual rents should be positive. Rents are measured as the difference between average net revenues and the winning bid. Let $w_{t}$ and $v_{t}$ denote, respectively, the winning bid and our estimate of the realization of $V$ on tract $t$. Then the average value of rents for a sample of tracts of size $T$ is given by

$$
R=T^{-1} \sum_{t=1}^{T}\left[v_{t}-w_{t}\right]
$$

A second related test is that firms should expect to earn positive rents conditional on submitting a winning bid. Let $Z_{0 t}$ denote an index of characteristics of tract $t$ that are observable to the bidders (including $l_{t}$ ). Define $\widehat{w}_{i t}$ as the estimate of bidder i's valuation of the tract conditional upon winning with a bid of $b_{i t}$. It is obtained by estimating the function $E\left[V_{t} \mid B_{i t}=b, M_{i t}<b, Z_{0 t}=z_{0}\right]$ (see Appendix A.2 for details) and then evaluating this function at $b=b_{i t}$. The difference between $\widehat{w}_{i t}$ and $b_{i t}$ represents bidder i's expected profit margin conditional on winning tract $t$. The average profit margin for a sample of tracts of size $T$ is

$$
D=T^{-1} \sum_{t=1}^{T} \sum_{i=1}^{n_{t}} n_{t}^{-1}\left[\widehat{w}_{i t}-b_{i t}\right] .
$$

Furthermore, a comparison of rents and bidder profit margins across low and high $l$ tracts should reveal whether firms take into account the "winner's curse". If they failed to do so, then actual rents and margins should be substantially lower on high $l$ tracts than low $l$ tracts, and perhaps even negative.

The values of $D$ and $R$ for high and low $l$ tracts are reported in the table below. The standard deviations of the statistics are reported in parentheses. They are obtained from the bootstrap procedure that is described in the appendix.

\begin{tabular}{|c|c|c|}
\hline & $R$ & $D$ \\
\hline Low $l$ & $\$ 3.75(1.73)$ & $\$ 3.76(1.54)$ \\
\hline High $l$ & $\$ 3.65(2.89)$ & $\$ 3.56(1.30)$ \\
\hline
\end{tabular}

The average rents and margins are essentially the same on each set of tracts, and do not vary significantly with the level of competition. Thus, there is no adverse selection associated with winning, which is consistent with bidders anticipating the "winner's curse". We also calculated the average margin as a percentage of average value. The percentages on low and high competition tracts are $65 \%$ and $38 \%$ respectively. 
Are the magnitude of the rents plausible? We have referred to $R$ as the average rent but it is more accurately called the average quasi-rent since it does not include entry costs. Under the assumption that entry rates are determined by a zero (expected) profit condition, the expected rent from bidding on a tract should be approximately equal to total entry costs. A bidder's entry cost consists primarily of the price of a seismic survey and the cost of hiring engineers to study the survey data and prepare a bid. The magnitude of these costs is probably several hundreds of thousands of dollars per bidder per tract. These costs have to be recovered from rents earned on tracts won. Consequently, given measurement error, one is unlikely to reject the hypothesis that the average rent is equal to total entry costs in either set of tracts.

Did bidders bid less than their expected tract value? The rent and bid margins calculated above suggest that they did so in aggregate but a stronger test of rationality is to examine whether they did so at every bid level. We wish to test the restriction that

$$
E\left[V_{t} \mid B_{i t}=b, Z_{0 t}=z_{0}\right]>b
$$

at all bid levels. We refer to this test as (T1). Rational bidders in a common value environment should also anticipate the "bad news" associated with winning. That is, at every bid level, they should bid less than their expected value of the tract conditional on winning,

$$
E\left[V_{t} \mid B_{i t}=b, M_{i t}<b, Z_{0 t}=z_{0}\right]>b .
$$

We refer to this test as (T2). The difference between these two conditional expectations is a measure of the "winner's curse",

$$
\kappa(b)=E\left[V_{t} \mid B_{i t}=b, Z_{0 t}=z_{0}\right]-E\left[V_{t} \mid B_{i t}=b, M_{i t}<b, Z_{0 t}=z_{0}\right]
$$

The key tract characteristic on which we condition the tests is the number of potential bidders. In a symmetric common values environment, the winner's curse measure should be greater when there is more competition, as winning is worse news the larger the number of potential bidders. We examine this prediction. Note that both of the above tests and our measure of "winner's curse" can be applied to individual bidders, or to a set of bidders.

Figure 1 plots estimates of the average value of $V_{t}$ conditional on $b$ and the average value conditional on the event of winning at $b$ for low $l$ tracts, where there is less potential competition. In both cases, the estimates of the conditional expectations are computed from a univariate locally linear regression. The former estimate, which is the basis for (T1), employs the full sample of bids submitted by Big12 firms, whereas the latter uses the subsample of winning bids by the Big12. Details of the nonparametric estimation procedures can be found in the Appendix. We also plot a 
45 degree line, so that these conditional expectations can be compared to the relevant bid level. We use a (base 10) log scale for both axes of the figure. Both conditional expectation functions are above the 45 degree line over the observed range of bids, which means that Big12 bidders satisfy the rationality tests (T1) and (T2) in the aggregate. Throughout the range of bids, the average value of tracts won by large firms at $b$ is substantially lower than the average value of tracts that received a bid of $b$. Furthermore, the difference increases weakly with $b$. The difference is depicted in levels in Figure 1a, as a function of log bid. For example, at a bid of $\$ 1$ million, the difference is on the order of $\$ 2$ million. A block bootstrap procedure, described in Appendix B, is employed to derive a one-sided $95 \%$ confidence band for our estimate of the winner's curse. The confidence band depicted in Figure 1a indicates that the difference between the two expectation functions is marginally significant at the $5 \%$ level.

Figure 2 plots estimates of the same two conditional expectations for high $l$ tracts. The results are qualitatively similar to those reported for low $l$ tracts. Figure $2 \mathrm{a}$ presents our estimate of "winner's curse" and its confidence band for tracts with more competition. Measured relative to bid, the "winner's curse" appears to be larger for the high $l$ tracts than the low $l$ tracts. For example, the difference between bidding $\$ 1$ million and winning at $\$ 1$ million is on the order of $\$ 5$ million on high $l$ tracts. Figure $2 \mathrm{a}$ indicates that the difference between the two expectation functions is significant for bids less than $\$ 1$ million, but marginally significant at higher bid levels. It suggests that the "winner's curse" is present and increases weakly with bid. However, most of the large firms appear to anticipate the "curse" and bid on the order of $1 / 3 \mathrm{rd}$ of the average value conditional on winning. 91

The above analysis of aggregate bidding on the part of Big12 firms indicates that they pass our tests of rational bidding, (T1) and (T2).T Averaged across all bids, we estimate the value of the winner's curse to be $\$ 2.73$ million on low $l$ tracts, and $\$ 6.13$ million on high $l$ tracts. The respective standard errors are $\$ 1.18$ million and $\$ 1.61$ million. The estimate of winner's curse is $107 \%$ of the average winning bid on low $l$ tracts, and $75 \%$ on high $l$ tracts.

In order to determine whether the results are affected by the categorization of tracts, we replicated the calculations above for three sets of tracts, according to whether the number of potential bidders was less than six, between six and eight, or

\footnotetext{
${ }^{9}$ These results are derived under the hypothesis of common values and the reader should not interpret them as evidence for the common value model. As we explain in Section 7, they are not inconsistent with an affiliated private values model.

${ }^{10} \mathrm{We}$ also computed the conditional expectations for individual firms and found that most firms bid rationally. However, Texaco not only failed to anticipate the "winner's curse", it also failed to bid less than the average value conditional on its bid. Its $E\left[V_{t} \mid B_{i t}=b\right]$ curve lies everywhere below b.
} 
more than eight. The results are qualitatively similar, with the ordering preserved, although the confidence bands are much wider.

\section{$5 \quad$ Tests of Equilibrium Bidding}

In this section we present the tests of equilibrium bidding. Define

$$
\xi\left(b, G\left(b ; z_{0}\right)\right)=b+\frac{G_{M_{i t} \mid B_{i t}, Z_{0 t}}\left(b \mid b, z_{0}\right)}{g_{M_{i t} \mid B_{i t}, Z_{0 t}}\left(b \mid b, z_{0}\right)} .
$$

Similarly, we define the functions $\zeta\left(b, z_{0}\right)$ and $\gamma\left(b, z_{0}\right)$ by conditioning the expectations on tract characteristics. We wish to test the following restrictions: (i) $\xi\left(b, G\left(b ; z_{0}\right)\right)$ is strictly increasing in $b$, (ii) $\zeta\left(b, z_{0}\right)=\xi\left(b, G\left(b ; z_{0}\right)\right)$ and (iii) $\gamma\left(b, z_{0}\right)=\xi\left(b, G\left(b ; z_{0}\right)\right)$. If bidding is consistent with Bayesian Nash equilibrium, we should fail to reject (i) and (ii) and reject (iii), which we have defined as myopic bidding. The key tract characteristic that we observe is $l$ and we condition the tests on this variable. Bidders may observe other characteristics, but since the monotonicity and equality tests hold for each realization of $Z_{0 t}$, they must also hold in the aggregate. Therefore, an important property of the tests is that they are not sensitive to unobserved tract heterogeneity.

For each category of $l$, the bid data used to compute the conditional expectations $\zeta$ and $\gamma$ and the distribution function $G_{M_{i t} \mid B_{i t}, Z_{0 t}}$ are all pairs $\left(b_{i t}, m_{i t}\right)$ where $i$ indexes one of the Big12 firms and $m_{i t}$ is the maximum bid of the rivals or, in the absence of any rival bid, the reserve price. Recall that all bidders, including fringe bidders, are used to determine $m_{i t}$. Note that, for our purposes, it is sufficient to estimate the fraction of leases in which no potential rival submits a bid, $G_{M_{i t} \mid B_{i t}, Z_{0 t}}\left(r \mid b, z_{0}\right)$. Since we assume that we observe the set of potential rivals, it is straightforward to estimate this fraction. It would be much more difficult to estimate a structural model of bidding, in which case the fraction would have to be decomposed into the probability of becoming an active bidder, and the probability of bidding conditional on being active. The estimates of the conditional expectation $\zeta$ are computed from a bivariate locally linear regression. The estimates for $\xi$ are obtained from an estimate of the distribution $G_{M_{i t} \mid B_{i t}, Z_{0 t}}$.

Figure 3 depicts the estimates $\widehat{\xi}$ and $\widehat{\zeta}$ for low $l$ tracts. We use a (base 10) log scale for both axes of the Figure. We also plot a 45 degree line, so that $\widehat{\xi}$ and $\widehat{\zeta}$ can be compared to the relevant bid level. At any bid level $b$, the vertical difference between $\widehat{\xi}$ and the 45 degree line represents the factor by which bidders mark down their bid from their conditional expectation of tract value. The difference should be positive and Figure 3 reveals that this is the case throughout the range of bids. Note that the markdown in this case is relative to the bidder's expected value conditional 
on the event that the maximum signal among its rivals is equal to its own signal, not conditional on the event of winning. It should not be interpreted as a measure of the bidder's expected profit. The second point to note about $\widehat{\xi}$ is that it is strictly increasing throughout the range of bids. Hence, the above model passes our first test of equilibrium bidding, at least for the set of tracts where competition is low. The conditional expectation $\widehat{\zeta}$ also lies above the 45 degree line for the relevant range of bids and is increasing throughout. However, the difference $\widehat{\zeta}-\widehat{\xi}$ does not appear to be close to zero, except for bids near $\$ 1$ million. At higher bid levels, bidders appear to overestimate the value of the tract at the time of bidding.

Clearly, a formal test of equality of $\xi$ and $\zeta$ is needed. Such a test would probably contain elements of tests for the hypothesis that a nonparametric regression function is zero everywhere. It requires the derivation of the asymptotic distribution of an estimate of the (properly renormed) difference $\zeta-\xi$. In addition, since the small sample properties of such a test are likely to be poor a bootstrap correction may need to be applied. There is a fairly large literature on bootstrapped confidence bands of nonparametric regression estimators (see e.g. Hall $[9]$ and the references therein). Our estimator does not fit any of the standard cases and obtaining asymptotic refinements, i.e. confidence bands more accurate than those obtained by first order asymptotics, is very difficult. We are satisfied with obtaining confidence bands which are asymptotically valid. To account for spatial dependence, we employ a block bootstrap procedure (Künsch [14]), described in Appendix B. Figure 3a presents the results. The solid curve labelled "zero" gives the probability that the test statistic (i.e., $\widehat{\zeta}-\widehat{\xi}$ ) takes values less than zero. The dashed line gives the graph of the statistic itself to show its position relative to its own distribution. Rejection of the null hypothesis therefore occurs when the zero curve transcends one of the lines labelled "rejection band." At higher bid levels, the probability that the difference is negative is very close to one, which represents a clear rejection of the theory.

Figure 4 plots estimates of $\widehat{\xi}$ and $\widehat{\zeta}$ for high $l$ tracts. As in the case of low $l$ tracts, $\widehat{\xi}$ is strictly increasing in bid and lies above the 45 degree line. Hence, Bayesian Nash equilibrium behavior is not rejected. The conditional expectation function $\widehat{\zeta}$ also lies above the 45 degree line, except at very low bid levels, and it is strictly increasing throughout. But, in contrast to the low $l$ case, the difference $\widehat{\zeta}-\widehat{\xi}$ is close to zero at most bid levels. Figure 4 a depicts a formal test of equality. The results indicate that the hypothesis of equilibrium bidding is not rejected at conventional confidence levels in the middle of the support of the bid distribution. There is some evidence of rejection at very low (i.e., less than $\$ 500$ thousand) and at high (more than $\$ 10$ million) bid levels.

We tested the equality of $\gamma$ and $\xi$ in exactly the same way as the equality of $\zeta$ and $\xi$. Here we simply report the results of the test. At conventional confidence levels, the 
myopic model of bidding was rejected for low $l$ and high $l$ tracts. We conclude from these tests that firms do take into account the "bad news" of winning in formulating their bids, and for the more competitive tracts, they appear to get the magnitudes right.

An important feature of our tests is that we have not imposed any structure on the bidders' participation decisions in estimating $\xi$ and $\zeta$. We have simply assumed that expectations are consistent with the empirical law governing $M_{i t}$. An alternative estimation strategy is to exploit the underlying structure of the probability law of $M_{i t}$ to estimate $G_{M_{i t} \mid B_{i t}, Z_{0 t}}$ and $\zeta$ more efficiently using the entire vector of bids on each tract, including the "zeros", and estimates of the participation probabilities. We have not done so because we are not sufficiently confident of any specific participation model or our estimates of such a model to impose this structure. The main difficulty is with interpreting the "zeros". We would need to differentiate between potential bidders who did not bid because they were not active, and active bidders who chose not to bid because they did not obtain favorable information. We would also have to take a stand on whether bidders observe the number of active bidders. At this point, we prefer to forgo possible gains in efficiency in order to reduce the risk of misspecification.

Finally, we checked the robustness of our results by estimating all three functions for three categories of tracts, in which the number of potential bidders is low, medium or high. The results for the medium and high number cases are similar those of the high competition results reported above, whereas the results for five or fewer potential bidders are similar to those for six or fewer.

\section{The Bid Function}

In this section we propose an alternative to using equation (4) for estimating the bid function. We employ this strategy to estimate $\beta$ for high $l$ and low $l$ tracts and examine the prediction that bidders may bid less aggressively on tracts with more bidders.

Our approach to resolving the identification problem is to impose a moment restriction on the joint distribution of $\left(S_{i t}, V_{t}\right)$. Wilson [2.9] adopts the normalization $E\left[S_{i t} \mid V_{t}=v\right]=v$, where signals are measured so that the mean signal on a tract is equal to the tract's value. We instead assume that

$$
E\left[V_{t} \mid S_{i t}=s, Z_{0 t}=z_{0}\right]=s .
$$

Condition $(\mathrm{R})$ states that if a firm obtains a signal $s$ on a tract with characteristics $z_{0}$, then the expected value of that tract is equal to the value of the signal. Signals are normalized in terms of ex post value and we assume that firms' posterior estimates 
are not biased but correct on average. Identification of the bid function follows immediately from condition $(\mathrm{R})$ and monotonicity of the bid function since

$$
\begin{aligned}
s & =E\left[V_{t} \mid S_{i t}=s, Z_{0 t}=z_{0}\right]=E\left[V_{t} \mid B_{i t}=\beta\left(s, z_{0}\right), Z_{0 t}=z_{0}\right] \\
\Longrightarrow & \eta\left(b, z_{0}\right)=E\left[V_{t} \mid B_{i t}=b, Z_{0 t}=z_{0}\right] .
\end{aligned}
$$

Equation (6) defines an inverse bid function. ${ }^{\text {M }}$ It can be estimated as follows. For every bid level $b$ on a tract with characteristics $z_{0}$, define a neighborhood (in the space of bids, not locations) $B\left(z_{0}\right)$ of $b$, and compute the average ex post value of all tracts with characteristics $\mathrm{z}$ that received a bid in $B\left(z_{0}\right)$. To implement this idea, we employ a kernel estimator of the mean ex post value in the neighborhood of any bid $b$ for tracts with similar characteristics.

Condition $(\mathrm{R})$ is more than a normalization assumption on the distribution of signals. It extends the conditional independence assumption, condition (ii) of the Information Assumptions, to include $Z_{0 t}$. Thus, tract characteristics may influence the participation decisions of potential bidders, but they do not affect an active bidder's beliefs about $V_{t}$ conditional on observing its seismic signal. If the sample is stratified according to some characteristic $z_{0}$, then the condition is a statement about the joint distribution of $\left(V_{t}, S_{i t}\right)$ and other characteristics that are observed by the bidders, but not necessarily by the econometrician, conditional on $z_{0}$. Bidding behavior depends upon $z_{0}$ since it affects the distribution of $N_{t}$ (and $K_{t}$ ). For example, $l_{t}$ is an element of $z_{0}$.

Figure 5 presents estimates of the bid functions for tracts with large and small numbers of potential bidders. That is, in Figure 5 we restrict our attention to one observable tract characteristic $z_{0}$, whether or not the number of potential bidders is relatively large, and stratify the sample according to that characteristic. The estimated bid function is not monotonic in the subsample with a large number of bidders, in the region of bids between $\$ 1$ million and $\$ 1.5$ million. This region is approximately the mode of the bid distribution for this subsample, and so non-monotonicity cannot be attributed to a small sample size.

Condition ( $\mathrm{R}$ ) allows us to examine the comparative static prediction that bidders may bid less aggressively when the number of bidders is high. More aggressive bidding with more competition is also consistent with common values, but our presumption is that in a comparison of tracts with seven or more potential bidders to those with six or fewer, the winner's curse effect will dominate the effects of more competition. Figure 5 indicates that firms did bid somewhat less aggressively on high $l$ tracts than low $l$ tracts for a given signal. Figure 6 presents the corresponding estimate of the density of private signals for high and low $l$ tracts. Clearly, the distribution of signals

\footnotetext{
${ }^{11}$ As one of the referees has observed, condition $\mathrm{R}$ can also be used to identify the common value model provided data on ex post values are available in addition to bid data.
} 
on high $l$ tracts stochastically dominates (in the first order sense) the distribution of signals on the low $l$ tracts.

In some sense, our identifying assumption leads us to a nonparametric reverse regression of ex post value on bid and tract characteristics. The alternative identifying restriction, that the conditional mean of signals is the ex post value (i.e., $E\left[S_{i t} \mid V_{t}=\right.$ $v]=v$, or $E\left[S_{i t} \mid V_{t}=v, Z_{0 t}=z_{0}\right]=v$ ) would lead us to regress bid on value and tract characteristics. One problem with the alternative condition is that it is unlikely to be satisfied for high values of $V_{t}$, as well as zero values. In our data, there is less variability in bids than in our measure of ex post value, which equals zero on many tracts. A second problem with the alternative method is that ex post value is measured with error. One would favor the results of the reverse regression under the supposition that the measurement error is relatively severe, and, consistent with this supposition, the estimated slope of the bid function from the regression of bid on value is much less than that from the reverse regression.

These comparative statics results are suggestive, rather than definitive, because of the maintained assumptions, the Information Assumptions and condition ( $\mathrm{R}$ ). We also computed the relationship between bids and ex post payoffs conditional on the local neighborhood variables described in Section 3.2, in addition to conditioning on our measure of competition, but these results were not informative. A problem with the neighborhood variables is that they combine both ex ante and ex post information. The latter characteristic is problematic for the purpose of computing bid functions, given the spatial correlation in information and returns. Nevertheless, these neighborhood variables may be useful in estimating bid participation models.

\section{The Common Value Assumption}

The analysis of the previous sections and our interpretation of the results presumes that the bidding environment for oil and gas auctions is pure common value. In contrast, Li, Perrigne and Vuong [18] adopt the alternative assumption that the bidding environment is private values. The OCS auctions probably contain both common and private valuation components and as such are best described by a general affiliated values model. The question that we address in this section is whether the data suggest that the common component is a quantitatively more significant factor in the bidder valuations than the private component.

The argument for the common value case is that the firms are uncertain about common components of the value of the lease being sold, such as the size of any oil or gas deposits under the tract, the prices of oil and gas over the likely production horizon if the lease is productive, and the common costs of exploration and development. The first component is likely to matter, because firms may have private information 
about the size of the deposits based on the seismic data they obtain, especially their interpretation of that data.

Alternatively, one might argue that there is little discrepancy in private assessments of these common components, and instead that valuations differ because of differences in bidder specific components of valuations. The most likely sources of bidder payoff heterogeneity are the private components of exploration and drilling costs. Bidders are not likely to differ in their valuation of recovered deposits, to the extent that there is a well developed market for oil and gas. Under this alternative view, valuations are best modelled as private, although they may be affiliated because of the common unknown components of payoffs that may be correlated with publicly available information.

One may be tempted to argue that the results described in Figure 5 that bidders bid less aggressively in more competitive auctions are inconsistent with the assumption of private values. This would be valid if the private values are independent draws since, in that case, more competition leads to more aggressive bidding. However, Pinkse and Tan [24] show that in a class of affiliated private value environments the equilibrium bid function is not monotonically increasing in the number of bidders. Consequently, the fact that bids or even the winning bid are not increasing in the number of bidders is not conclusive evidence of common values.

Haile, Hong and Shum [ 8$]$ provide a test for distinguishing between the two kinds of environments that is based on equation (4). Define

$$
\widehat{\sigma}_{i t}=\widehat{\xi}\left(b_{i t}, \widehat{G}_{t}\left(b_{i t} ; z_{0 t}\right)\right)
$$

as the pseudo-value corresponding to bidder i's bid on tract t. Under the hypothesis of private values, this is an estimate of bidder i's valuation of tract $t$ but, under the hypothesis of common values, it is an estimate of $w\left(\eta\left(b_{i t}\right), \eta\left(b_{i t}\right)\right)$. Exogenous variation in the number of bidders can distinguish between these two interpretations. The empirical distribution of pseudo-values should be the same on low $l$ tracts as it is on high $l$ tracts if values are private, and it should be stochastically increasing in $l$ if the common component is important. The difficulty with applying this test to our data is unobserved tract heterogeneity. That is, consistent with our model of entry, the number of potential bidders may be correlated with tract value. The empirical distribution of $V_{t}$ is stochastically increasing in $l_{t}$ so, not surprisingly, bidders bid more on average on tracts with higher values of $l_{t}$.

A similar problem arises in trying to interpret the results presented in Figures 1 and 2 as evidence against private values. Absent unobserved heterogeneity, this conclusion would be correct since winning should not affect valuations in a private values environment. But, to see why unobserved heterogeneity matters, consider an APV setting. At a given bid level $b$, the bid is more likely to win if the idiosyncratic 
component of valuation is favorable. Hence the expected common component of valuations is lower conditional on winning. That is, there is a selection effect associated with conditioning on winning. Furthermore, the magnitude of the selection effect is higher on high $l$ tracts than on low $l$ tracts.

Consider, for example, the APV case in which bidder $i$ 's private value on tract $t$ is $V_{i t}$, where the $V_{i t}$ 's are conditionally independent and identically distributed given an unknown common component $V_{t}$. Our winner's curse measure

$$
\begin{aligned}
\kappa(b) & =E\left[V_{t} \mid B_{i t}=b\right]-E\left[V_{t} \mid B_{i t}=b, M_{i t} \leq b\right] \\
& =E\left[V_{t} \mid V_{i t}=\eta(b)\right]-E\left[V_{t} \mid V_{i t}=\eta(b), Y_{i t} \leq \eta(b)\right]
\end{aligned}
$$

where $\eta(\cdot)$ is the inverse of the equilibrium APV strategy and $Y_{i t}=\max _{j=i} V_{j t}$. Because $\left(V_{t}, V_{i t}, Y_{i t}\right)$ are affiliated, $\kappa(b)$ is strictly positive. Hence a positive value of $\kappa(b)$ does not rule out an APV environment. A positive value is inconsistent with an IPV environment, however. Moreover, in this APV example $\kappa(b)$ is increasing in the number of potential bidders.

The condition that the reserve price is binding can be useful. In a private value environment, $\xi$ must satisfy the boundary condition, $\lim _{b \downarrow r} \xi(b, G(b))=r$, which implies

$$
\lim _{b \downarrow r} \frac{G_{M_{i t} \mid B_{i t}}(b \mid b)}{g_{M_{i t} \mid B_{i t}}(b \mid b)} \longrightarrow 0 .
$$

By contrast, in a common values environment, $\xi$ is discontinuous at $r$, which implies that

$$
\lim _{b \downarrow r} \frac{G_{M_{i t} \mid B_{i t}}(b \mid b)}{g_{M_{i t} \mid B_{i t}}(b \mid b)} \longrightarrow c>0 .
$$

Therefore, it is possible in principle to distinguish between the two models by examining the behavior of $G_{M_{i t} \mid B_{i t}}$ near the reserve price. [2] Unfortunately, the reserve price in OCS auctions is not fixed. The government frequently rejected high bids near the announced minimum bid of $\$ 15$ per acre and, as a result, there are too few bids in this range to implement the test with any confidence. It might be possible to estimate the rejection decision of the government, i.e., the probability of accepting the high bid $b$, in conjunction with the empirical distribution of the highest rival bid, and then interpret $G_{M_{i t} \mid B_{i t}}$ as the probability that bidder i's bid is the highest and is accepted.

The approach that we adopt is to compute rents and profit margins under the hypotheses of private values and evaluate their plausibility. Let $w_{t}$ denote the winning

\footnotetext{
${ }^{12} \mathrm{~A}$ similar result holds for second-price auctions. Milgrom and Weber [22] observe that, in a CV environment, the difference between $E\left[V_{t} \mid S_{i t}=s^{*}, Y_{i t} \leq s^{*}\right]$ and the amount that $s^{*}$ bids, $E\left[V_{t} \mid S_{i t}=s^{*}, Y_{i t}=s^{*}\right]$, implies a lower bound for the distribution of bids that is strictly above the reserve price, $r$. No such gap should be present in a private value environment.
} 
bid on tract $t$ and define $\widehat{\sigma}_{1: t}=\widehat{\xi}\left(w_{t}\right)$ as the estimated private valuation of the winning bidder on tract $t$. Then the average value of rents under the private values hypothesis for a sample of tracts of size $T$ is given by

$$
\widetilde{R}=T^{-1} \sum_{t=1}^{T}\left[\widehat{\sigma}_{1: t}-w_{t}\right] .
$$

The average value of the bidder's profit margin can be defined as

$$
\widetilde{D}=T^{-1} \sum_{t=1}^{T} \sum_{i=1}^{n_{t}} n_{t}^{-1}\left[\widehat{\sigma}_{i t}-b_{i t}\right] .
$$

The table below reports the estimates of $\widetilde{R}$ and $\widetilde{D}$ for high and low $l$ tracts.

\begin{tabular}{|c|c|c|}
\hline & $\widetilde{R}$ & $\widetilde{D}$ \\
\hline Low $l$ & $\$ 19.0(2.62)$ & $\$ 14.65(1.67)$ \\
\hline High $l$ & $\$ 22.9(2.50)$ & $\$ 14.43(1.30)$ \\
\hline
\end{tabular}

Even after accounting for entry costs, private value rents seem quite large. What type of barriers to entry prevent bidders from increasing their participation rates to take advantage of rents in order of $\$ 20$ million? The magnitudes of the bid margins tells a similar story. Bidders marked down their bids independently of the number of potential bidders and by slightly more than $\$ 14$ million. Under private values, the percentage markdowns at the average are $88 \%$ for low $l$ tracts and $72 \%$ for high $l$ tracts. In other words, firms are bidding slightly more than $1 / 9$ of their estimate of the bidder specific value on low $l$ tracts, and less than $1 / 3$ on high $l$ tracts.

A related difficulty with assuming private values alone is that there is considerable within tract variation in bids (Porter [25]). For example, the second highest bid on a given tract averages about 56 per cent of the highest bid. In a symmetric private values model, such extreme variation in bids can be rationalized only if there is large variation in the private components of values. Yet the variation in valuations necessary to generate the observed variation in bids is an implausible order of magnitude. The large variation in bids accounts for the large implied markdowns we compute, as rational bidders can shade their bids considerably without lowering the probability of winning too much.

In summary, the OCS lease auctions probably contain both common and private valuation components, and hence are best described by a general affiliated values model, but the data suggest that the former components are more important. 


\section{Conclusion}

The main conclusions to be drawn from the preceding empirical analysis are (1) that the "winner's curse" is evident in the data and (2) that the bidders are aware of its presence and bid accordingly. Bidding behavior appears to be largely consistent with a symmetric common value environment, given our measure of potential competition and our measure of ex post returns. In contrast, some features of bidding behavior appear to be inconsistent with a private values environment. To repeat, the bidders' valuations in OCS auctions probably have both private and common components, but the common components appear to be important.

The theoretical model of the paper may be employed to examine the participation decisions of the potential bidders, and thereby obtain more efficient estimates of bidding rules. We hope to pursue this direction in future work. 


\section{References}

[1] Bajari, P. (1998): "Econometrics of the First Price Auction with Asymmetric Bidders," mimeo, Harvard University.

[2] Bajari, P. (1998): "Econometrics of Sealed Bid Auctions," Proceedings of the Business and Economic Statistics Section of the American Statistical Association, 41-49.

[3] Bajari, P. and A. Hortacsu (2000): "Winner's Curse, Reserve Prices and Endogenous Entry: Empirical Insights from eBay Auctions," mimeo, Stanford University.

[4] Baldwin, L., R. Marshall and J.F. Richard (1997): "Bidder Collusion at Forest Service Timber Sales," Journal of Political Economy, 105, 657-699.

[5] Donald, S., and H. Paarsch (1993): "Piecewise Maximum Likelihood Estimation in Empirical Models of Auctions," International Economic Review, 34, 121-148.

[6] Elyakime, B., J.J. Laffont, P. Loisel and Q. Vuong (1994): "First-Price, SealedBid Auctions with Secret Reservation Prices," Annales d'Economie et de Statistique, 34, 115-141.

[7] Guerre, E., I. Perrigne and Q. Vuong (2000): "Optimal Nonparametric Estimation of First-Price Auctions," Econometrica, 68, 525-574.

[8] Haile, P., H. Hong and M. Shum (2000): "Nonparametric Tests for Common Values in First-Price Auctions," mimeo, University of Wisconsin.

[9] Hall, P. (1992): The Bootstrap and Edgeworth Expansion, New York: Springer.

[10] Hendricks, K., and R. Porter (1988): “An Empirical Study of An Auction with Asymmetric Information," American Economic Review, 78, 865-883.

[11] Hendricks, K., R. Porter and C. Wilson (1994): "Auctions For Oil and Gas Leases with an Informed Bidder and a Random Reservation Price," Econometrica, 62, 1415-1444.

[12] Hong, H., and M. Shum (1999): "Structural Estimation of First Price Auction Models: Measuring Common Values and the Winner's Curse," mimeo, Princeton University.

[13] Klemperer, P. (1998): "Auctions with Almost Common Values: The 'Wallet game' and its Applications," European Economic Review, 42, 757-769. 
[14] Künsch, H. (1989): "The Jackknife and the Bootstrap for General Stationary Observations," Annals of Statistics, 17, 1217-1241.

[15] Laffont, J.J., H. Ossard and Q. Vuong (1995): "Econometrics of First-Price Auctions," Econometrica, 63, 953-980.

[16] Laffont, J.J., and Q. Vuong (1996): "Structural Analysis of Auction Data," American Economic Review, Papers and Proceedings, 86, 414-420.

[17] Li, T., I. Perrigne and Q. Vuong (2000): "Structural Estimation of the Affiliated Private Values Auction Model", mimeo, University of Southern California.

[18] Li, T., I. Perrigne and Q. Vuong (2000): "Conditionally Independent Private Information in OCS Wildcat Auctions", Journal of Econometrics, 98, 129-161.

[19] Marshall, R., and M. Raiff (1997): "The Impact of Synergies on Bidding in the Georgia School Milk Market," mimeo, Pennsylvania State University.

[20] McAfee, P., D. Quan, and D. Vincent (1996): "How to Set Minimum Acceptable Bids, with an Application to Real Estate Auctions," mimeo.

[21] McAfee, P., and D. Vincent (1992): "Updating the Reserve Price in CommonValue Auctions," American Economic Review, Papers and Proceedings, 82, 512518.

[22] Milgrom, P., and R. Weber (1982): "A Theory of Auctions and Competitive Bidding," Econometrica, 50, 1089-1122.

[23] Paarsch, H. (1992): "Deciding between the Common and Private Value Paradigms in Empirical Models of Auctions," Journal of Econometrics, 51, 191215.

[24] Pinkse, J., and G. Tan (2000): "Fewer Bidders can Increase Price in First-Price Auctions with Affiliated Private Values," mimeo.

[25] Porter, R. (1995): "The Role of Information in U.S. Offshore Oil and Gas Lease Auctions," Econometrica, 63, 1-27.

[26] Smiley, A. (1979): Competitive Bidding Under Uncertainty: The Case of Offshore Oil, Ballinger, Cambridge.

[27] Stone, C. (1977): "Consistent Nonparametric Regression," Annals of Statistics $5,595-645$. 
[28] Wahba, G. (1977): "A Survey of some Smoothing Problems and the Method of Generalized Cross-Validation for Solving Them," in Applications of Statistics, ed. P. Kirshnaiah, North Holland, Amsterdam.

[29] Wilson, R. (1977): "A Bidding Model of Perfect Competition," Review of Economic Studies, 44, 511-518. 


\section{Appendix}

\section{A Estimation Methods}

There are four functions that need to be estimated: $E\left[V_{t} \mid B_{i t}=b\right], E\left[V_{t} \mid B_{i t}=b, M_{i t}<\right.$ $b], E\left[V_{t} \mid B_{i t}=b, M_{i t}=b\right]$, and $\xi(b, G)$. We estimate each of these functions nonparametrically. The procedures are described below. All computations employ log (base 10) bids.

\section{A.1 Local Linear Regression, One Regressor}

We estimate the conditional expectation function $E\left[V_{t} \mid B_{i t}=b\right]$ on the sample of all bids $\left\{b_{i t}\right\}$ (within the same number of potential bidders class) and tract values $\left\{v_{t}\right\}$ using the following formula at each value of $b$ (Stone [27])

$$
\left\{\widehat{v}(b), \widehat{r}_{v}(b)\right\}=\arg \min _{v, r} \sum_{t=1}^{T} \sum_{i=1}^{n_{t}}\left\{v_{t}-v-r\left(b-b_{i t}\right)\right\}^{2} k\left(\frac{b-b_{i t}}{h}\right) \frac{1}{n_{t}}
$$

where $T$ is the number of tracts in the sample, $h$ is the bandwidth and $k$ the kernel. We use a standard normal kernel and a bandwidth chosen by visual inspection. [3

The conditional expectation $E\left[V_{t} \mid B_{i t}=b, M_{i t}<b\right]$ is estimated on the sample of winning bids $\left\{w_{t}\right\}$ and tract values $\left\{v_{t}\right\}$ using the formula,

$$
\left\{\widehat{w}(b), \widehat{r}_{w}(b)\right\}=\arg \min _{v, r} \sum_{t=1}^{T}\left\{v_{t}-v-r\left(b-w_{t}\right)\right\}^{2} k\left(\frac{b-w_{i t}}{h}\right) .
$$

Each term in the summation of equation (6) includes a weight equal to the reciprocal of the number of bids on tract. This weighting is necessary to compare $E\left[V_{t} \mid B_{i t}=b, M_{i t}<b\right]$ and the other statistics, since only one bid per tract is used for the computation of $E\left[V_{t} \mid B_{t}=b, M_{i t}<b\right]$, whereas all bids are used in the computation of the other statistics.

\section{A.2 Local Linear Regression, Two Regressors}

The conditional expectation $E\left[V_{t} \mid B_{i t}=b, M_{i t}=b\right]$ is estimated on the sample of all bid pairs $\left\{b_{i t}, m_{i t}\right\}$ and tract values $\left\{v_{t}\right\}$ (within the same number of potential bidders

\footnotetext{
${ }^{13}$ We experimented with an automatic bandwidth selection procedure, generalized cross validation (Wahba [28] ), but this procedure broke down because of the presence of some extreme revenue values.
} 
class) using the formula

$$
\begin{aligned}
& \{\widehat{v}(b, m), \widehat{r}(b, m)\} \\
& =\arg \min _{v, r_{1}, r_{2}} \sum_{t=1}^{T} \sum_{i=1}^{n_{t}} \\
& \quad\left\{v_{t}-v-r_{1}\left(b-b_{i t}\right)-r_{2}\left(m-m_{i t}\right)\right\}^{2} k\left(\frac{b-b_{i t}}{h_{b}}\right) k\left(\frac{m-m_{i t}}{h_{m}}\right) \frac{1}{n_{t}},
\end{aligned}
$$

where $h_{b}$ and $h_{m}$ are bandwidths.

\section{A.3 Pseudo-Values}

As in Li, Perrigne and Vuong [17], we estimate $G_{L}$ and $g_{L}$, the distribution and density of base $10 \log$ bids, and then derive the ratio of the distribution and the density of bid levels according to (omitting subscripts) $G(b \mid b) / g(b \mid b)=b \log \left(G_{L} / g_{L}\right)$. Note that $G_{M_{i t} \mid B_{i t}}(b \mid b)=P\left[M_{i t}<b \mid B_{i t}=b\right]=E\left[I\left(M_{i t}<b\right) \mid B_{i t}=b\right]$, where $I$ is an indicator function. We estimate $G_{M_{i t} \mid B_{i t}}(b \mid b) / g_{M_{i t} \mid B_{i t}}(b \mid b)$ using the formula

$$
\frac{h_{m} \sum_{t=1}^{T} \sum_{i=1}^{n_{t}} k\left(\left[b-b_{i t}\right] / h_{b}\right) I\left(m_{i t}<b\right) n_{t}^{-1}}{\sum_{t=1}^{T} \sum_{i=1}^{n_{t}} k\left(\frac{b-b_{i t}}{h_{b}}\right) k\left(\frac{m-m_{i t}}{h_{m}}\right) \frac{1}{n_{t}}} .
$$

Since $G_{M_{i t} \mid B_{i t}}(b \mid b)$ is discontinuous at $b=r$, estimates of $g_{M_{i t} \mid B_{i t}}(b \mid b)$ close to $b=r$ are biased upward but are not inconsistent. If In our sample no tracts received bids at the announced reserve price.

\section{B Bootstrap}

The bootstrap procedure used is a spatial block bootstrap. Except for the rent calculations, the number of bootstrap replications is 10,000. For the rent calculations, the estimated standard deviations are based on 1,000 bootstrap replications. The computations were carried out on a $300 \mathrm{MHz}$ PowerMac running Mac OS X Server.

The bootstrap procedure is not pivotal and the bootstrap approximation error therefore decreases at the same rate as when the asymptotic distribution is derived by first order asymptotics (Hall [] $]$ ).

The procedure is outlined below.

1. Number all tracts 1 through $T$.

\footnotetext{
${ }^{14}$ However, they are not uniformly consistent.
} 
2. Denote by $q_{t}$ the reciprocal of the number of tracts in $\Lambda_{t}$, the neighborhood of tract $t$, including tract $t$ itself.

3. Let $Q_{t}=\sum_{s=1}^{t} q_{s} / \sum_{s=1}^{T} q_{s}$

4. Draw a random number $r$ in $[0,1]$.

5. Find the tract $t$ whose value of $Q_{t}$ is the closest to $\mathrm{r}$.

6. Add tract $t$ to the bootstrap sample.

7. Add all tracts in the neighborhood of tract $t$ to the bootstrap sample.

8. Repeat steps $4-7$ until the number of tracts in the bootstrap sample is greater than or equal to $T$.

9. Eliminate tracts at the end of the bootstrap sample such as to make the number of bootstrap tracts equal to the number of sample tracts.

10. Compute all statistics for the bootstrap sample.

11. Repeat steps 4 through $10 R$ times, where $R$ denotes the number of replications.

Several points about the procedure are worth noting. First, the block bootstrap is needed to accommodate dependence across tracts. In the 'normal' bootstrap one would make $T$ independent draws from the tract distribution. We make a number of independent draws from the neighborhood distribution, such as to make the number of tracts in the bootstrap sample equal to $T$. Second, because a tract is selected either directly or as part of the neighborhood of a directly selected tract, tracts in regions where a lot of tracts are bid are more likely to be selected. This is countered in step 5 by making the probability that tract $t$ is selected directly inversely proportional to the number of tracts in $\Lambda_{t}$. The procedure is not perfect, but it eliminates most of the variability. Finally, the number of bids varies a little from bootstrap sample to bootstrap sample, but generally by less than $5 \%$ in either direction. 


\section{TABLE 1}

Wildcat Bidding by the Twelve Firms and Consortia with the Most Bids

\begin{tabular}{|c|c|c|c|c|}
\hline Firms and Consortia & $\begin{array}{r}\text { Number of } \\
\text { Solo Bids } \\
\end{array}$ & $\begin{array}{r}\text { Number of } \\
\text { Joint Bids }\end{array}$ & $\begin{array}{r}\text { Potential } \\
\text { Bidder } \\
\end{array}$ & $\begin{array}{r}\text { Participation } \\
\text { Rate }\end{array}$ \\
\hline Arco/Getty/Cities/Cont. & 437 & 114 & 1027 & 0.54 \\
\hline Standard Oil of California & 408 & 76 & 1022 & 0.47 \\
\hline Standard Oil of Indiana & 132 & 276 & 905 & 0.45 \\
\hline Shell Oil & 444 & 3 & 981 & 0.46 \\
\hline Gulf Oil & 201 & 81 & 801 & 0.35 \\
\hline Exxon & 325 & 42 & 812 & 0.45 \\
\hline Texaco & 114 & 178 & 823 & 0.35 \\
\hline Mobil & 48 & 163 & 700 & 0.30 \\
\hline Union Oil of California & 95 & 201 & 805 & 0.37 \\
\hline Phillips & 98 & 65 & 498 & 0.33 \\
\hline Sun Oil & 241 & 93 & 723 & 0.46 \\
\hline Forest & 195 & $\mathbf{0}$ & 493 & 0.40 \\
\hline
\end{tabular}

TABLE 2

Summary of Wildcat Sales, 1954-1970

\begin{tabular}{|c|c|c|c|c|c|c|c|c|c|}
\hline Sale Date & $\begin{array}{l}\text { \#Tracts } \\
\text { Offered }\end{array}$ & $\begin{array}{c}\text { \#Tracts } \\
\text { Bid }\end{array}$ & $\begin{array}{c}\text { \#Tracts } \\
\text { Big } 12 \\
\text { Bid } \\
\end{array}$ & $\begin{array}{l}\text { \#Tracts } \\
\text { Sold }\end{array}$ & $\begin{array}{l}\text { \#Tracts } \\
\text { Drilled }\end{array}$ & \#Hits & $\begin{array}{c}\text { Mean } \\
\text { Rev }\end{array}$ & $\begin{array}{c}\text { Mean } \\
\text { NetRev }\end{array}$ & $\begin{array}{l}\text { Mean } \\
\text { Hibid }\end{array}$ \\
\hline 54-10-13 & 199 & 90 & 77 & 90 & 65 & 45 & 44.00 & 6.99 & 4.49 \\
\hline 54-11-09 & 38 & 19 & 17 & 19 & 10 & 4 & 13.38 & 0.46 & 4.27 \\
\hline $55-07-12$ & 210 & 117 & 92 & 117 & 64 & 27 & 30.62 & 2.23 & 3.14 \\
\hline $60-02-24$ & 385 & 173 & 141 & 147 & 117 & 61 & 89.25 & 21.61 & 4.97 \\
\hline $62-03-13$ & 401 & 211 & 169 & 206 & 165 & 79 & 56.57 & 11.17 & 2.47 \\
\hline $62-03-16$ & 410 & 210 & 169 & 205 & 169 & 79 & 52.59 & 9.69 & 3.75 \\
\hline $67-06-13$ & 206 & 172 & 142 & 158 & 130 & 53 & 67.09 & 10.55 & 7.80 \\
\hline $68-05-21$ & 169 & 141 & 110 & 110 & 71 & 16 & 12.21 & -0.87 & 10.72 \\
\hline $70-12-15$ & 127 & 127 & 57 & 119 & 112 & 64 & 68.76 & 19.60 & 15.18 \\
\hline Total & 2145 & 1260 & 974 & 1171 & 903 & 428 & 58.60 & 10.48 & 6.19 \\
\hline
\end{tabular}

*Dollar figures in millions of 1982 dollars. 


\section{TABLE 3}

Characteristics of Wildcat Tracts and Their Neighborhoods by Number of Potential Bidders*

Number of Potential Bidders $(l)$

\begin{tabular}{|c|c|c|c|c|c|c|c|c|c|c|c|c|c|c|}
\hline & $\mathbf{0}$ & 1 & 2 & 3 & 4 & 5 & 6 & 7 & 8 & 9 & 10 & 11 & 12 & Total \\
\hline \# of Tracts & 7 & 45 & 74 & 115 & 72 & 94 & 101 & 138 & 164 & 189 & 160 & 85 & 16 & 1260 \\
\hline Bids/Tract (All) & 1.00 & 1.13 & 1.55 & 1.99 & 2.17 & 2.84 & 2.80 & 3.94 & 3.65 & 5.12 & 5.11 & 5.36 & 4.25 & 3.62 \\
\hline Bids/Tract (12) & 0.00 & 0.91 & 1.24 & 1.53 & 1.64 & 2.33 & 2.32 & 3.01 & 2.65 & 3.77 & 3.51 & 3.66 & 2.94 & 2.67 \\
\hline Tract Hibid & 0.60 & 1.32 & 2.21 & 2.63 & 2.78 & 4.01 & 2.94 & 6.79 & 5.70 & 9.26 & 11.5 & 8.59 & 13.1 & 6.19 \\
\hline & $(0.38)$ & (1.72) & (3.82) & (4.38) & (4.08) & (6.63) & (3.62) & (11.3) & $(9.36)$ & (13.5) & (18.8) & (12.5) & (22.6) & (11.6) \\
\hline \%Tract Drilled & 66.7 & 62.2 & 54.9 & 71.8 & 73.9 & 79.3 & 73.2 & 81.4 & 79.6 & 82.3 & 80.0 & 84.2 & 100.0 & 77.1 \\
\hline$\%$ Hits & 25.0 & 39.1 & 38.5 & 45.6 & 41.7 & 50.8 & 50.7 & 47.6 & 41.3 & 47.7 & 54.2 & 54.7 & 46.7 & 47.4 \\
\hline Tract & 3.60 & 84.8 & 28.0 & 66.1 & 60.6 & 38.2 & 45.2 & 76.8 & 43.8 & 61.1 & 71.5 & 55.8 & 62.7 & 58.6 \\
\hline Revenue & $(0.0)$ & $(80.3)$ & (41.4) & (101) & (89.4) & (67.4) & (81.7) & (102) & (73.4) & (97.5) & (103) & $(66.6)$ & (89.2) & (89.8) \\
\hline Tract & -1.30 & 10.91 & 2.45 & 11.3 & 10.9 & 5.97 & 7.53 & 15.4 & 6.02 & 11.7 & 15.5 & 12.5 & 15.4 & 10.5 \\
\hline NetRev & (1.31) & (33.4) & (15.7) & (41.8) & (39.1) & (29.5) & (36.2) & (49.3) & (31.3) & (49.0) & (49.8) & (34.8) & (42.2) & (40.9) \\
\hline
\end{tabular}

*Dollar figures in millions of 1982 dollars, and refers to the means of the preceding sample. Standard deviations are in parentheses. 
Table 4: Bid Frequency Distribution

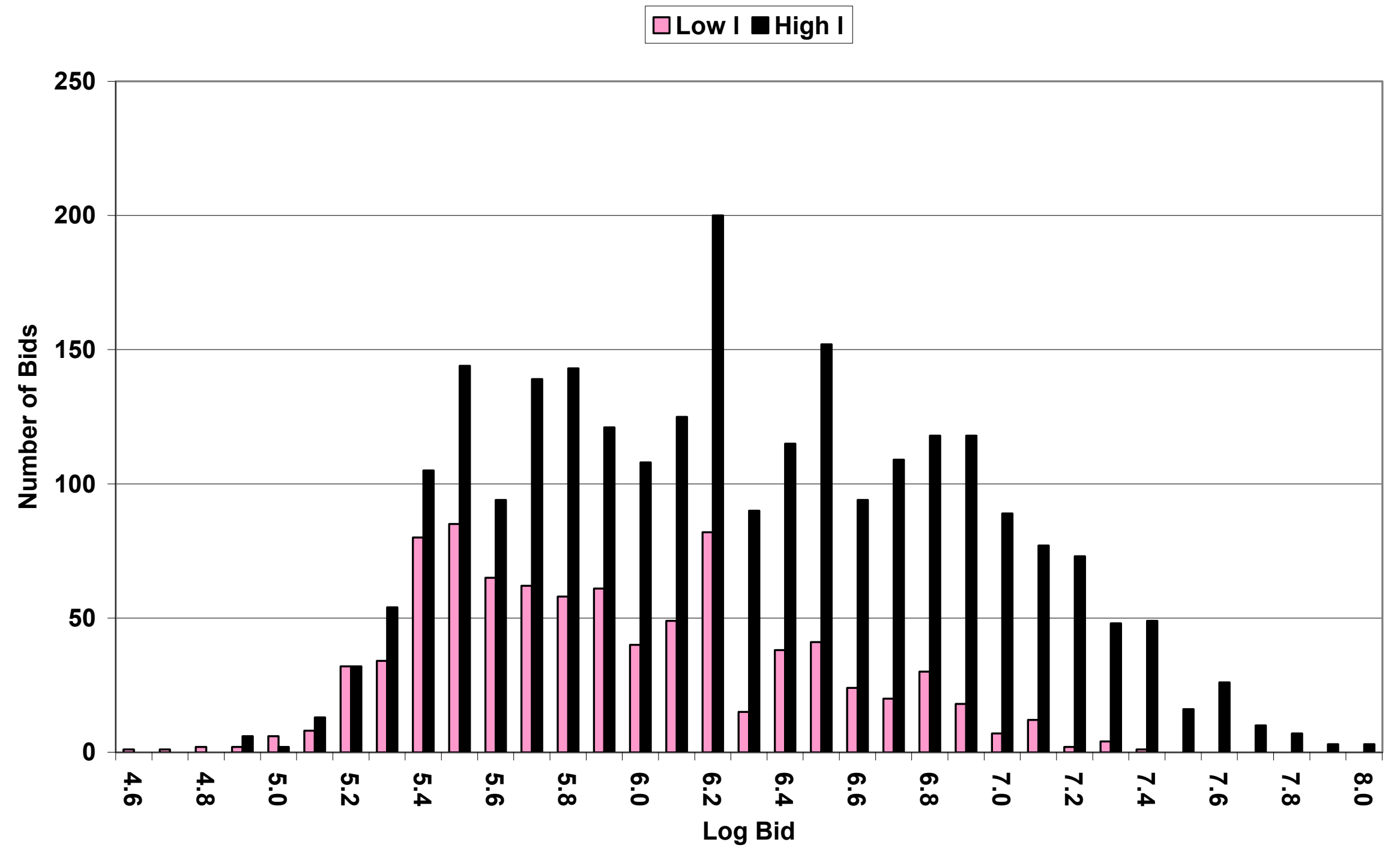


Figure 1: Test of Rational Bidding for Low 1 Tracts

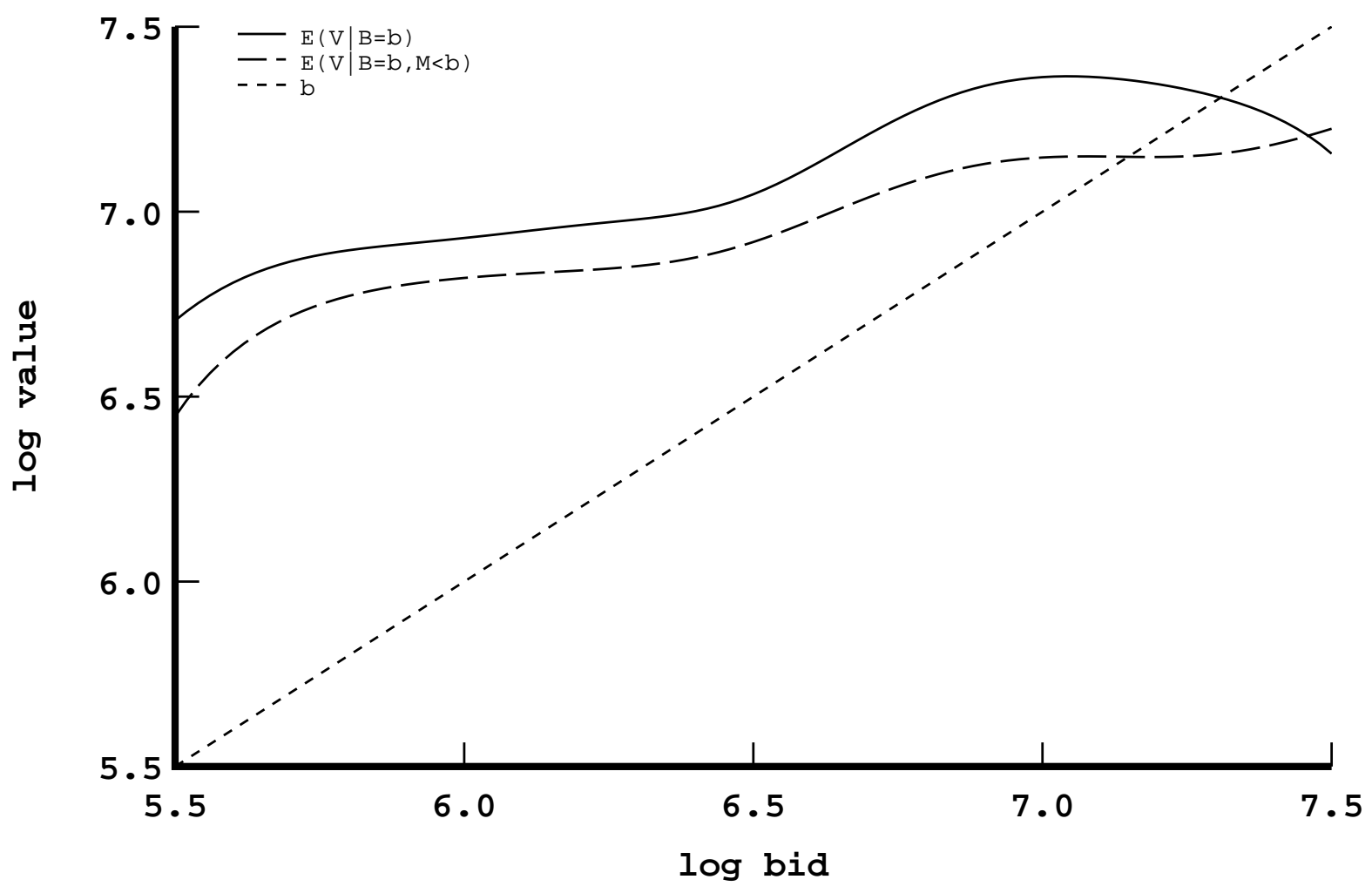

Figure 1a: Test of Rational Bidding for Low 1 Tracts

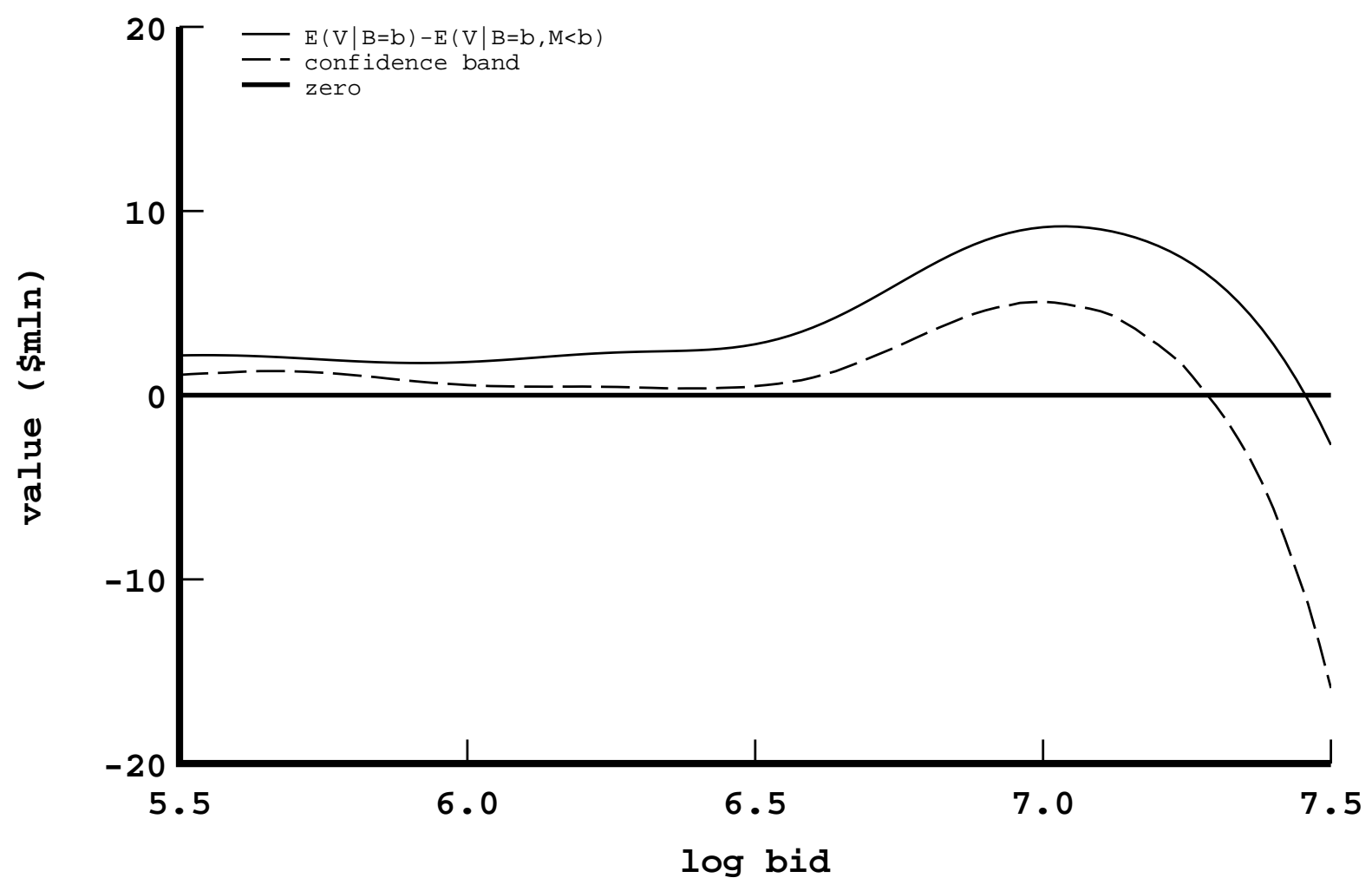


Figure 2: Test of Rational Bidding for High 1 Tracts

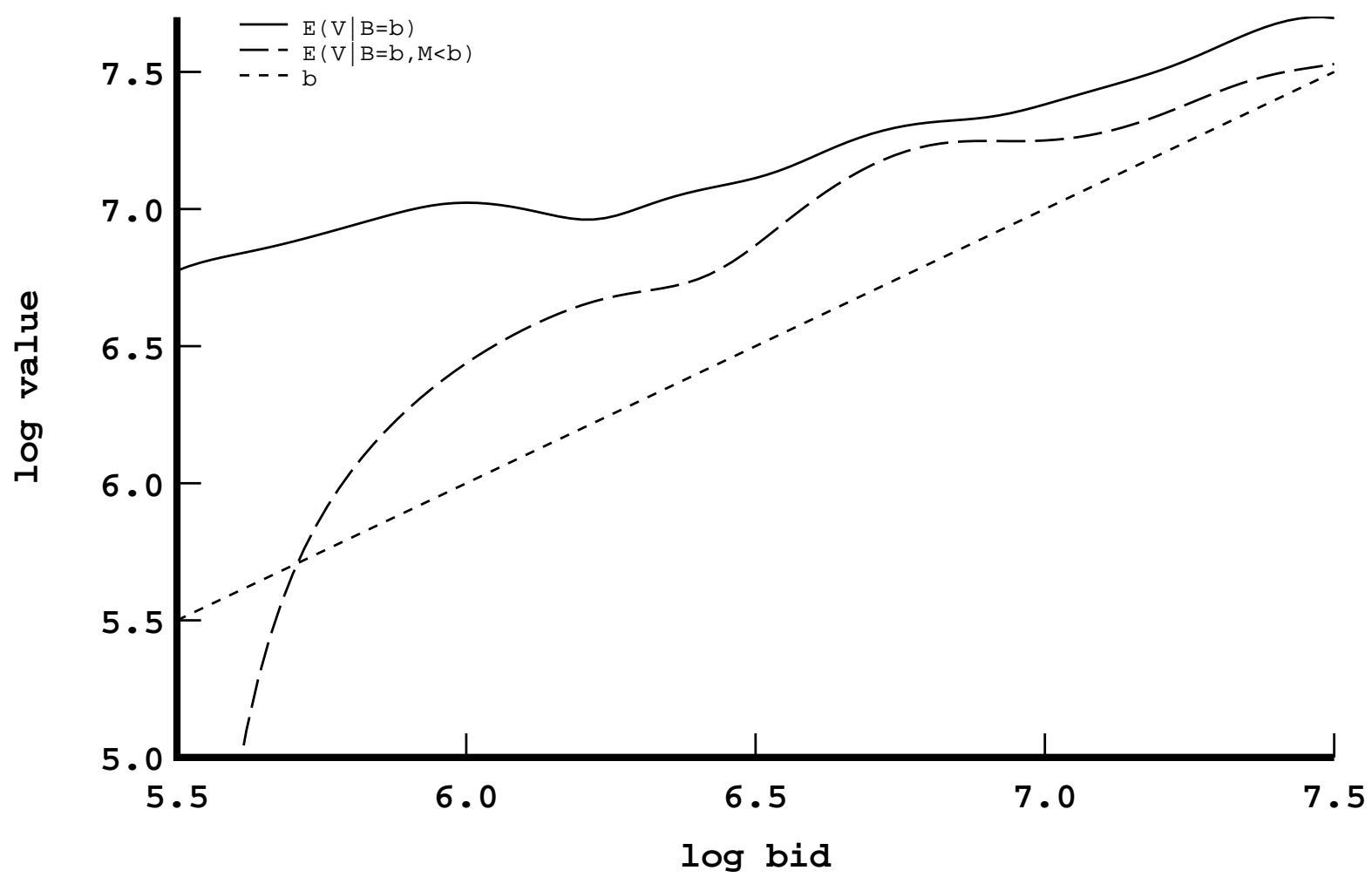

Figure 2a: Test of Rational Bidding for High 1 Tracts

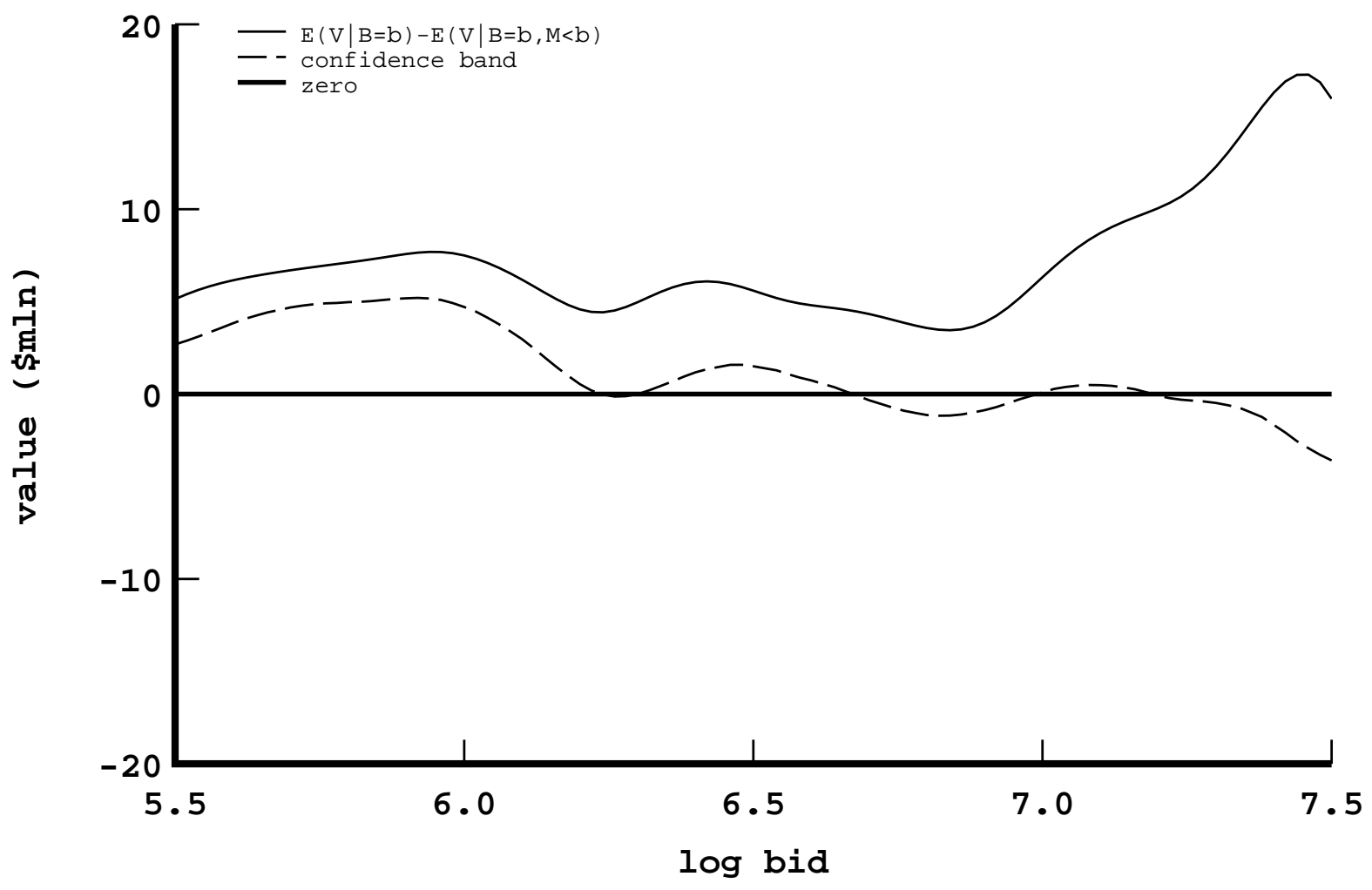


Figure 3: Bid Functions

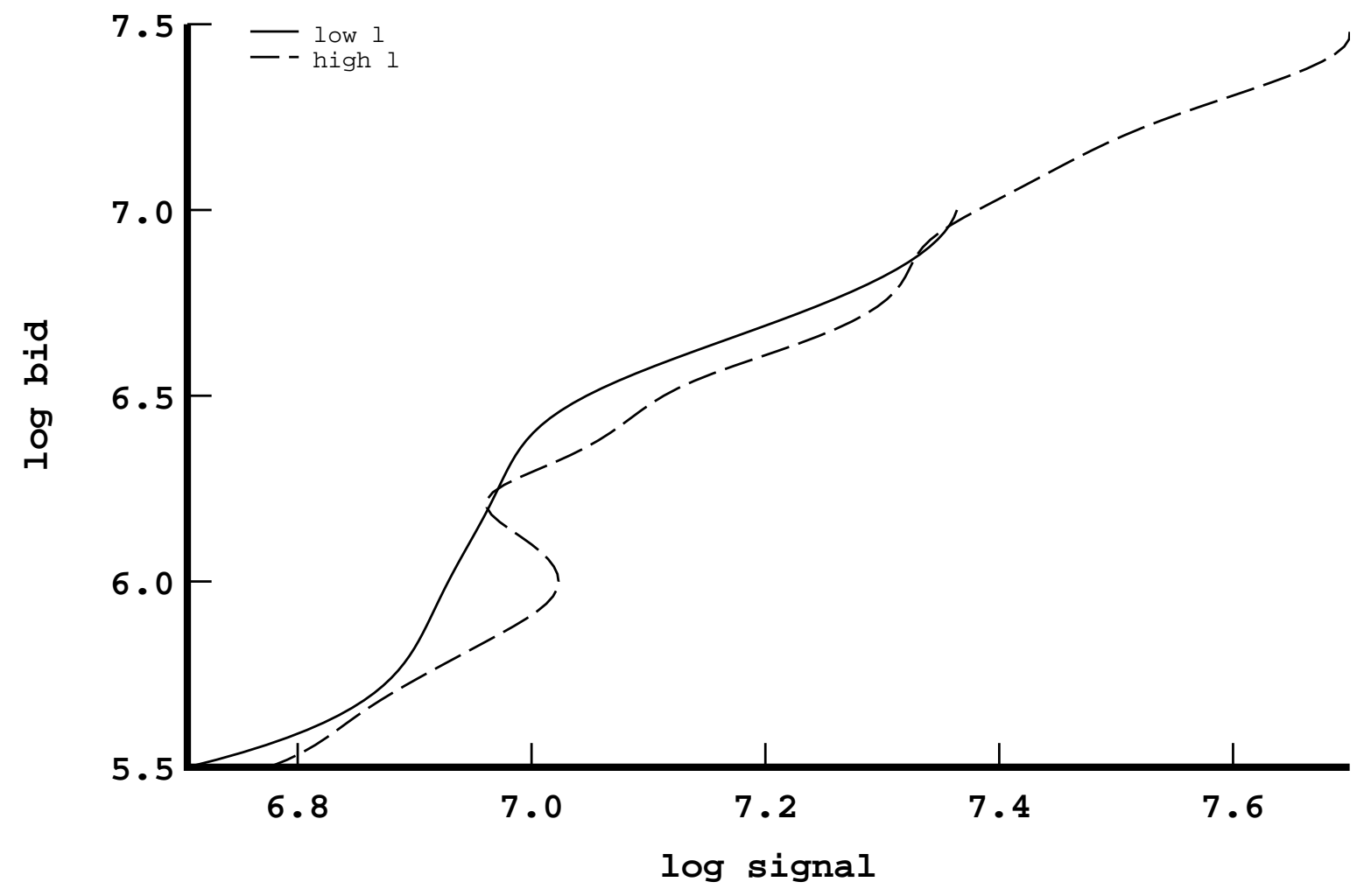

Figure 4: Signal Densities

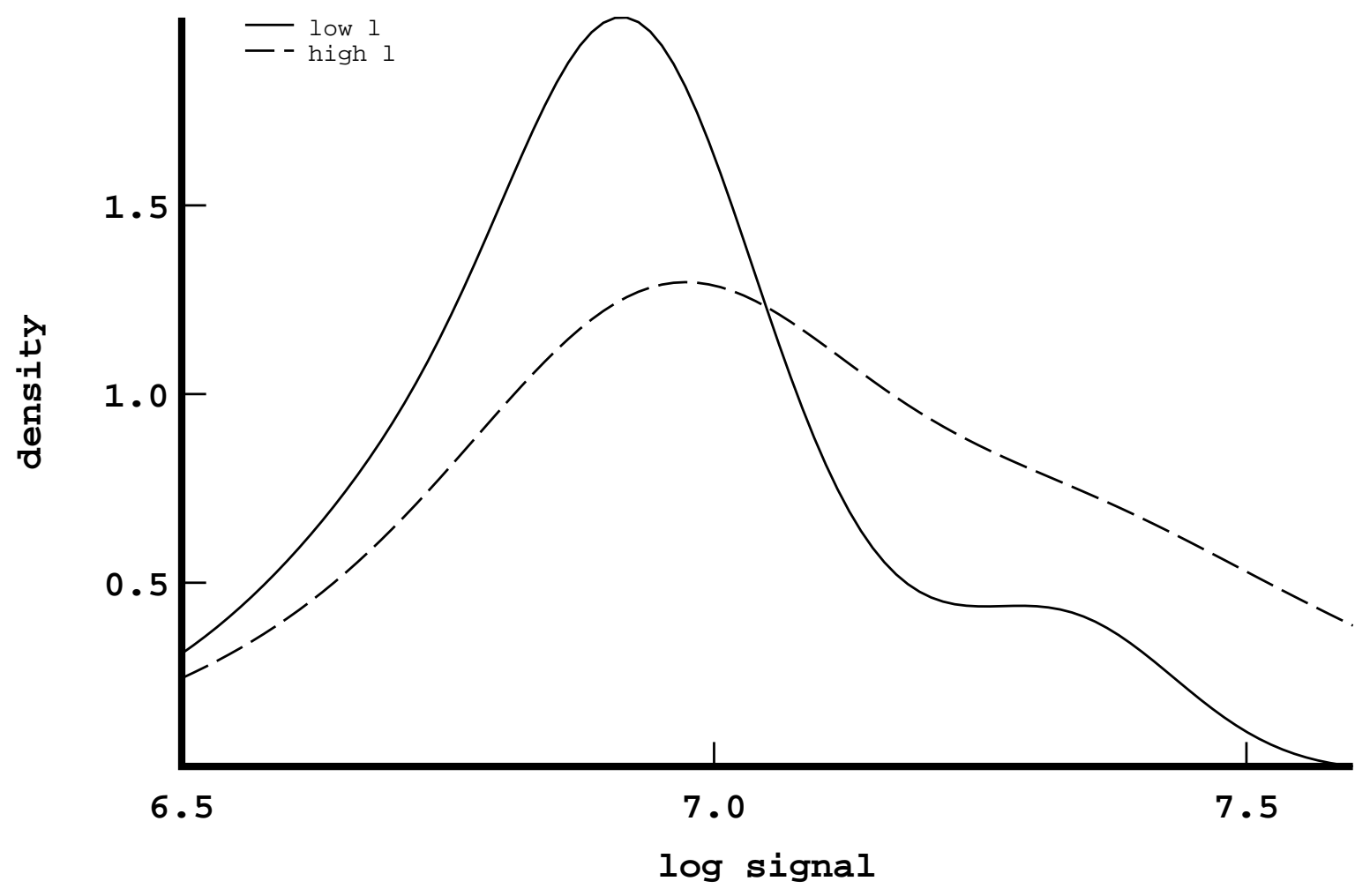




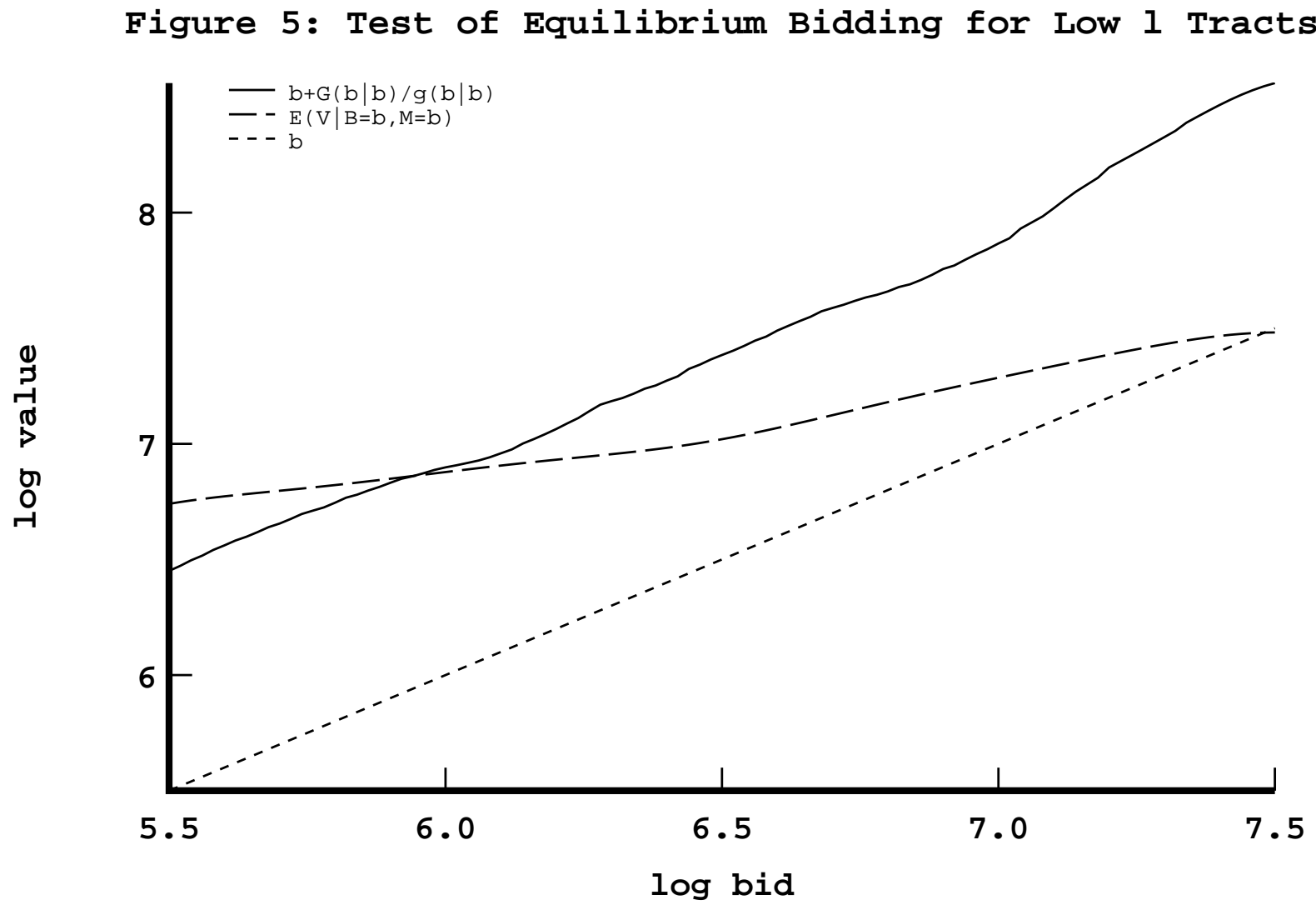

Figure 5a: Test of Equilibrium Bidding for Low 1 Tracts

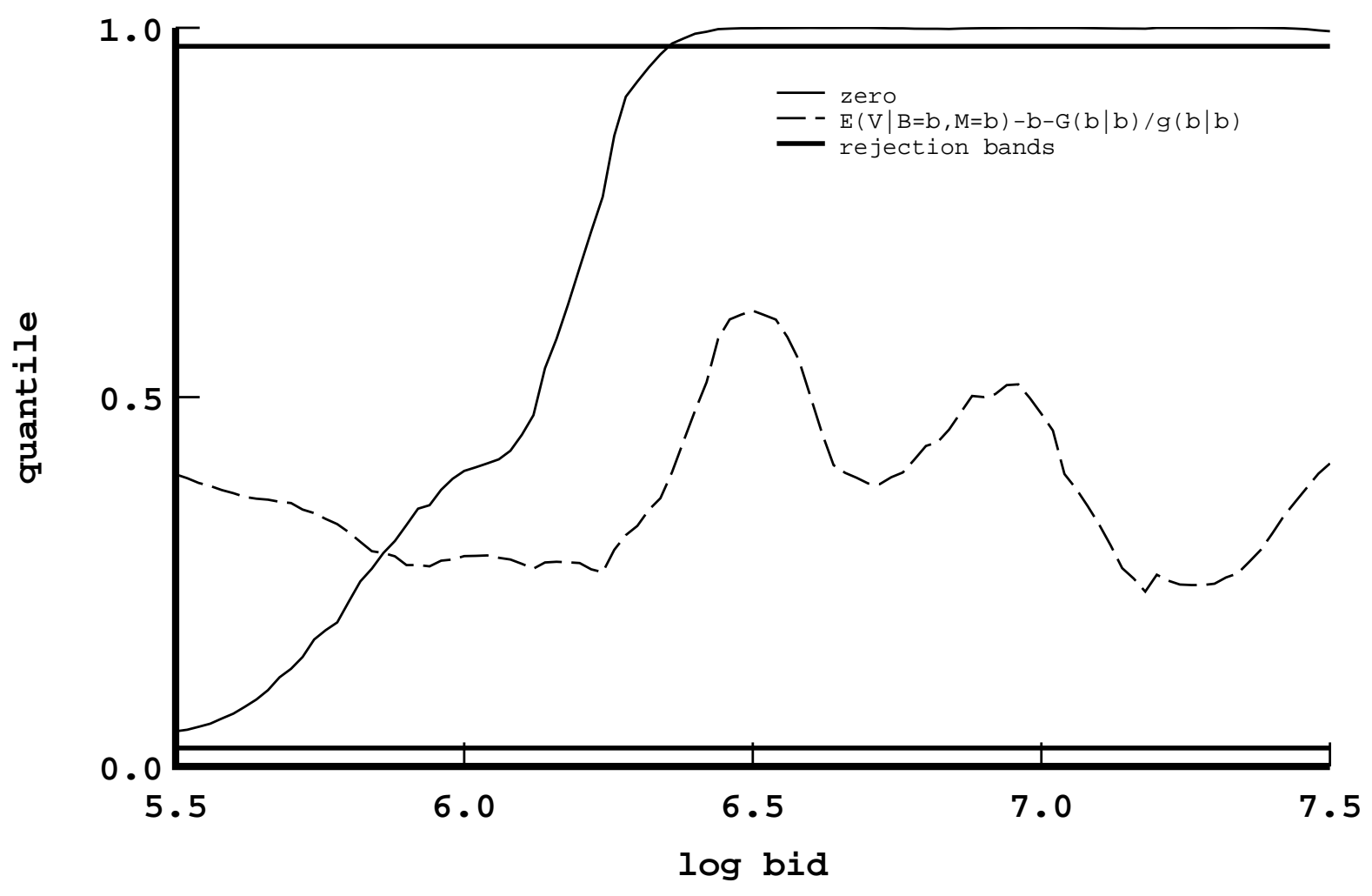


Figure 6: Test of Equilibrium Bidding for High 1 Tracts

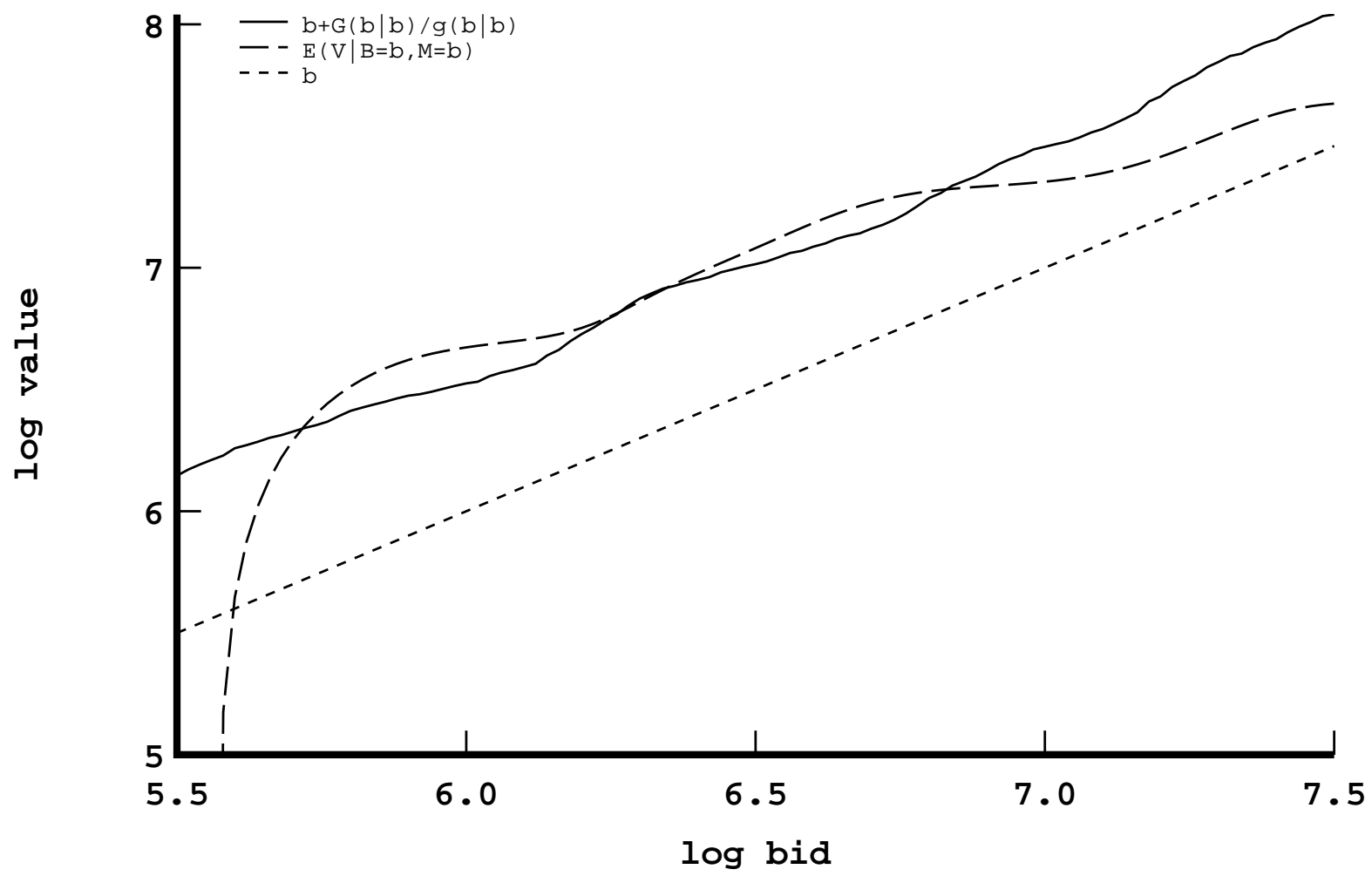

Figure 6a: Test of Equilibrium Bidding for High 1 Tracts

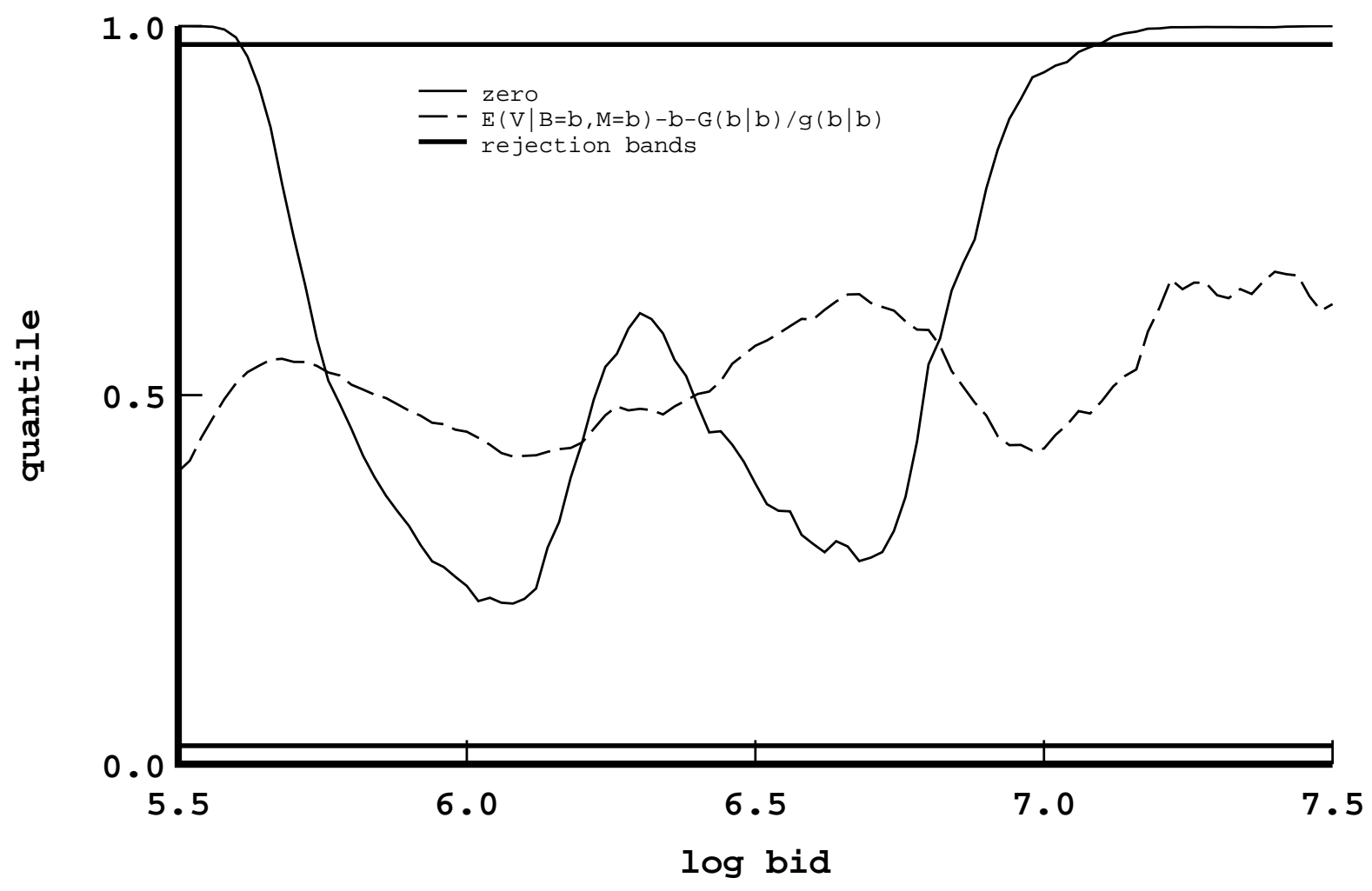

